\title{
Mitochondria as a target and central hub of energy division during cold stress in insects
}

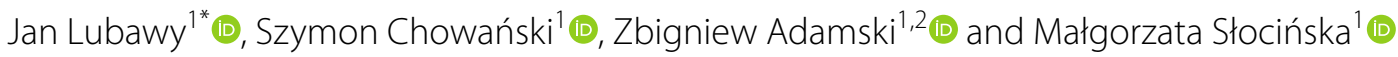

\begin{abstract}
Temperature stress is one of the crucial factors determining geographical distribution of insect species. Most of them are active in moderate temperatures, however some are capable of surviving in extremely high as well as low temperatures, including freezing. The tolerance of cold stress is a result of various adaptation strategies, among others the mitochondria are an important player. They supply cells with the most prominent energy carrier-ATP, needed for their life processes, but also take part in many other processes like growth, aging, protection against stress injuries or cell death. Under cold stress, the mitochondria activity changes in various manner, partially to minimize the damages caused by the cold stress, partially because of the decline in mitochondrial homeostasis by chill injuries. In the response to low temperature, modifications in mitochondrial gene expression, mtDNA amount or phosphorylation efficiency can be observed. So far study also showed an increase or decrease in mitochondria number, their shape and mitochondrial membrane permeability. Some of the changes are a trigger for apoptosis induced via mitochondrial pathway, that protects the whole organism against chill injuries occurring on the cellular level. In many cases, the observed modifications are not unequivocal and depend strongly on many factors including cold acclimation, duration and severity of cold stress or environmental conditions. In the presented article, we summarize the current knowledge about insect response to cold stress focusing on the role of mitochondria in that process considering differences in results obtained in different experimental conditions, as well as depending on insect species. These differentiated observations clearly indicate that it is still much to explore.
\end{abstract}

Keywords: Mitochondria, Cold stress, Bioenergetics, Enzymes activity, ATP, UCP, HSP, Apoptosis

\footnotetext{
*Correspondence: j.lubawy@amu.edu.pl

${ }^{1}$ Department of Animal Physiology and Developmental Biology, Institute

of Experimental Biology, Faculty of Biology, Adam Mickiewicz University, Poznan, Poland

Full list of author information is available at the end of the article
}

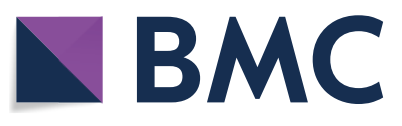

(c) The Author(s) 2021. Open Access This article is licensed under a Creative Commons Attribution 4.0 International License, which permits use, sharing, adaptation, distribution and reproduction in any medium or format, as long as you give appropriate credit to the original author(s) and the source, provide a link to the Creative Commons licence, and indicate if changes were made. The images or other third party material in this article are included in the article's Creative Commons licence, unless indicated otherwise in a credit line to the material. If material is not included in the article's Creative Commons licence and your intended use is not permitted by statutory regulation or exceeds the permitted use, you will need to obtain permission directly from the copyright holder. To view a copy of this licence, visit http://creativecommons.org/licenses/by/4.0/. The Creative Commons Public Domain Dedication waiver (http://creativeco mmons.org/publicdomain/zero/1.0/) applies to the data made available in this article, unless otherwise stated in a credit line to the data. 


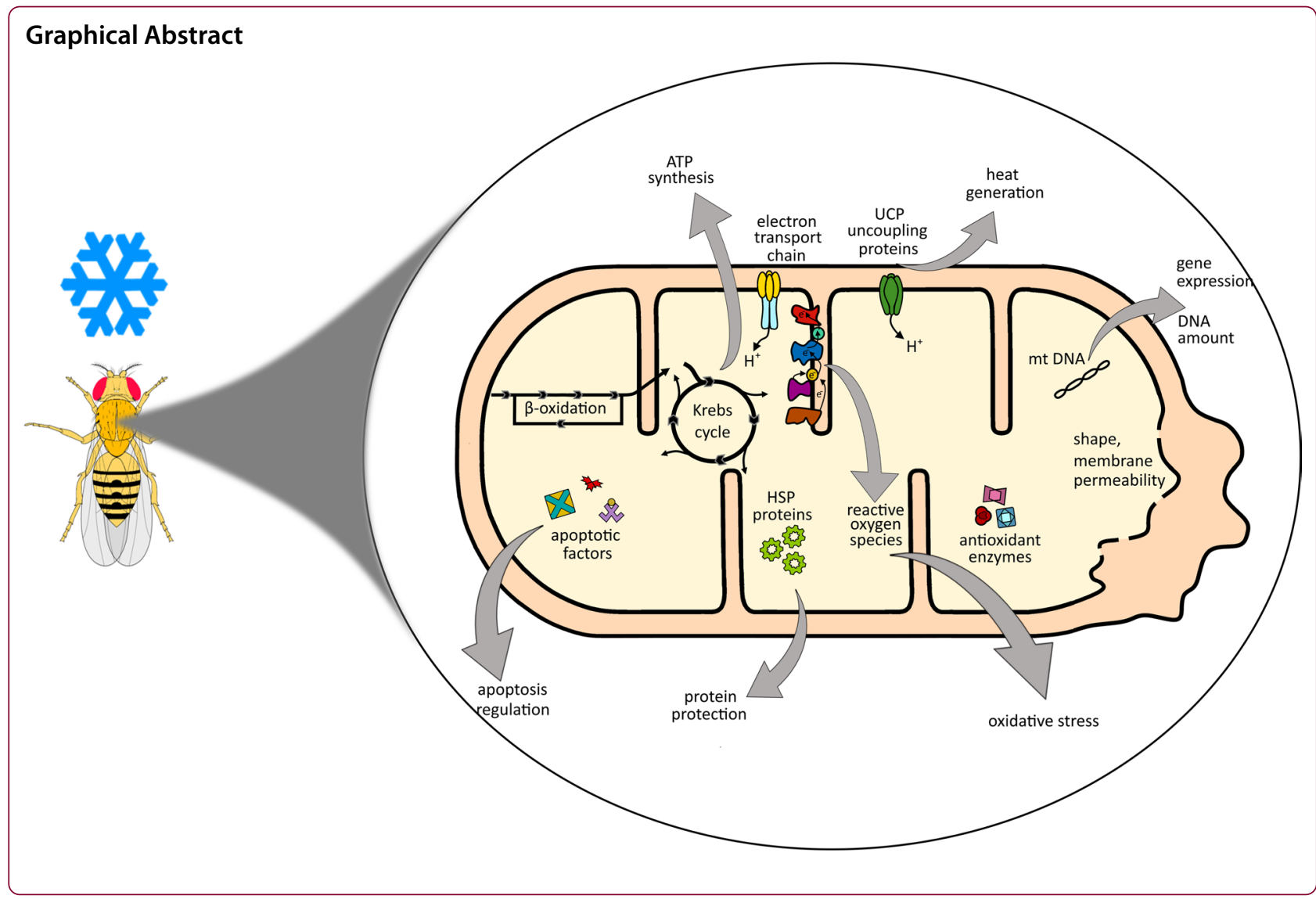

\section{Introduction}

All types of cells are active energetic units that need a constant supply of energy. In animal cells "power plants" which provide it are mitochondria. Mitochondria are a double membrane-bound organelle found in most eukaryotic organisms which provide energy from substances accumulated in food, ending in the production of a prominent energy carrier of the cell, ATP. According to endosymbiotic hypothesis, theses organelles were originally prokaryotic cells that became endosymbionts living inside the eukaryotes, implementing oxidative mechanisms generating energy [1]. However, this is not their only role, as mitochondria are associated with almost all major aspects of eukaryotic evolution from aging, senescence to reproduction and immune response [2-6]. They function as a cellular hub that links metabolism, stress sensing, signaling, and survival of the cell [5, 7, 8] (Fig. 1). Hence, it is not particularly surprising that mitochondria can play a role in environmental adaptations $[3,9,10]$.

Insects are constantly challenged by unfavorable environmental conditions such as pathogen infections, UV radiation, the action of insecticides, oxidative stress, and temperature-either high or low [11-15]. Temperature stress is without a doubt the most critical factor among abiotic stressors affecting the physiology of insects. Extreme temperatures or large temperature fluctuations can be harmful to ectothermic organisms either through direct effects, which include temperature-induced cellular or tissue injury and/or through indirect effects, e.g., limitations in their activity [16-20].

Maintaining cellular energy homeostasis is a challenge for insects, which are exposed to low stressful temperatures in nature. During their lifetimes, insects have the capacity to adjust their physiological mechanisms to promote cold tolerance and cope with sublethal thermal conditions, a phenomenon referred to as thermal acclimation [21-26]. Based on the ability to withstand and survive freeze stress (temperatures where its body fluids might be expected to freeze), insects fall into the following categories.

1. Chill susceptible insects die from cold-induced injuries before the formation of ice occurs within their bodies [27-29]. This strategy is sometimes referred to as cold-intolerance. For example, the larvae of the false codling moth, Thaumatotobia leucotreta (Lepidoptera: Tortricidae), freeze between -13 and $-22^{\circ} \mathrm{C}$ but are killed by brief exposures between -8 


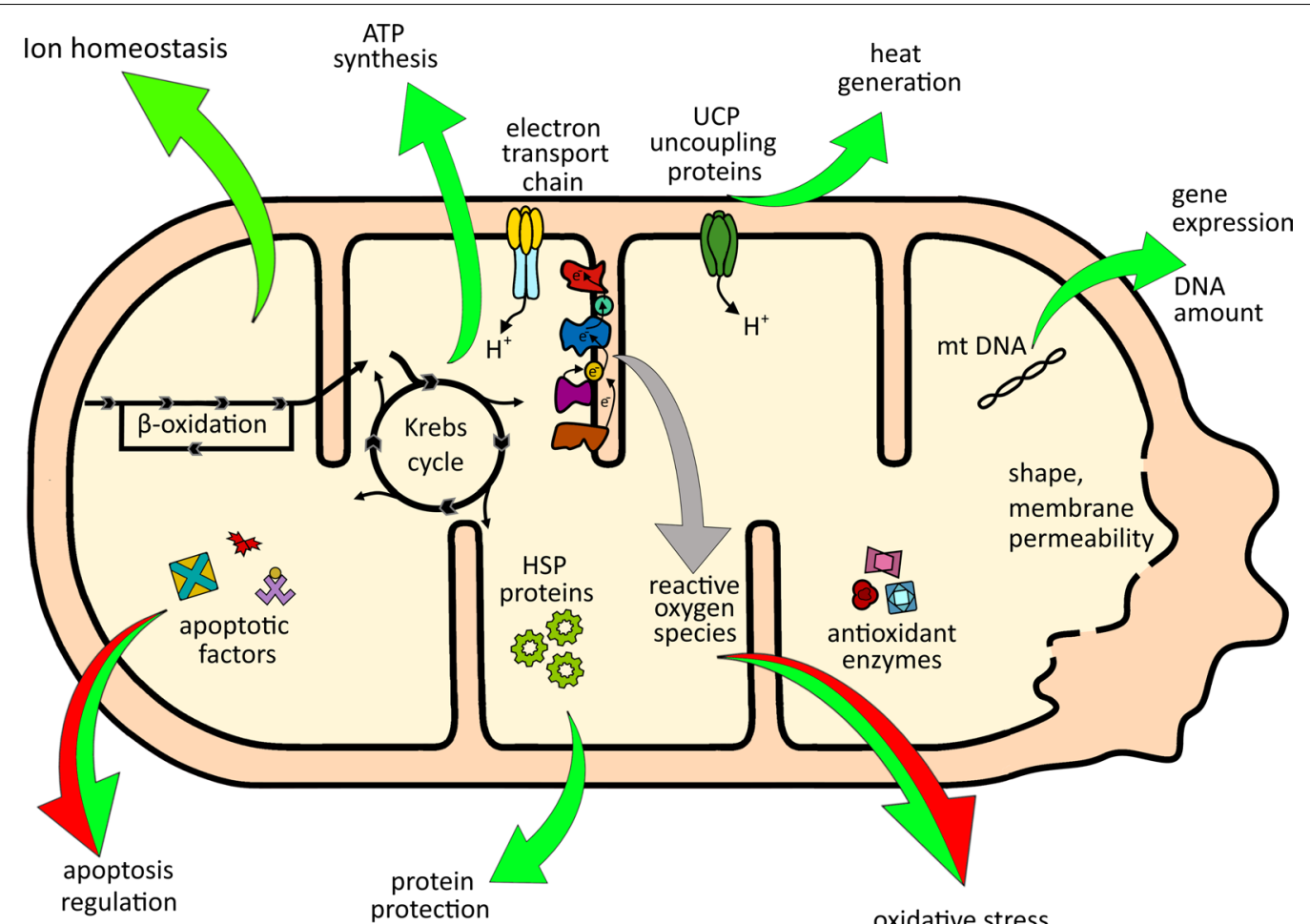

Fig. 1 The multi-directional role of mitochondria during cold stress. The mitochondria are both the target of cold stress and the central hub that coordinates the cell response to it. During cold stress, the energy metabolism of these organelles changes in order to maintain the functionality of the entire cell. Insects faced with cold stress change their cellular metabolism, which often results in increased accumulation of ROS by mitochondria. Consequently, the mitochondrial antioxidant system during cold stress is modulated to counteract the negative effects of cold-associated ROS formation [37]. It is also increasingly obvious that the mitochondrial integrity and cellular signaling associated with mitochondria are essential for sustaining ion and energetic homeostasis of the cell and its survival [28]. Tight regulation of apoptosis by mitochondrial pathway is essential for survival as the stimulated activity of caspases is not solely the indicator of apoptosis but besides, it demonstrates nonapoptotic functions i.e., control of a cell shape, cell migration or proliferation. Mitochondria may also take part in heat dissipation which is caused by uncoupling of the respiration by these organelles [55]. If these mechanisms fail to adapt the cell to prevail the cold stress and the accumulation of cold-injuries is increasing, the mitochondria commence the processes leading to the programmed cell death pathway via apoptosis to utilize and recycle damaged cells and their components [38]. Green arrows indicate mitochondria regulated processes leading to the cell survival pathway, whereas red arrows processes leading to cell death

and $-12{ }^{\circ} \mathrm{C}[30]$. The cold tolerance of these chillsusceptible insects is therefore determined by their ability to survive exposure to temperatures above their freezing point $[29,31,32]$. Vast majority of insects fall into this category as they are not able to handle severe sub-zero temperatures (for details see Overgaard et al. [28], Overgaard and MacMillan [27] and references within). More recently, species falling to this category have been further classified into chill-susceptible or chill-tolerant species, depending on their relative sensitivity to low temperature [27].

2. The second strategy is freeze-avoidance. Species utilizing this strategy are capable of surviving low temperatures by lowering their freezing point of extracellular compartments of their body by supercooling via accumulation of cryoprotectants. For example, prepupae of the emerald ash borer, Agrilus planipennis can survive prolonged exposures to subzero temperatures, provided they do not freeze, and in the winter have SCPs (Supercooling point; the temperature at which spontaneous ice formation is initiated in the insects body fluids) below $-25^{\circ} \mathrm{C}$ [33].

3. Lastly, there are examples of insects that can tolerate and survive freezing of their tissues and bodyfreeze-tolerant ones. The most profound example of insect using this strategy is the fly Chymomyza costata, which is capable of surviving immersion in liquid nitrogen [34].

Regardless of the strategy used, in some insects also occur the phenomenon of diapause. Perfect examples are two species of goldenrod gall insects, Epiblema scudderiana and Eurosta solidaginis, the first being freezeavoiding and the second being a freeze-tolerant species. 
Yet, for both winter survival includes entry into diapause [35]. Diapause is an adaptation assisting in survival of insects through periods of harsh environmental conditions and adverse seasons. Many insects distributed in the temperate zones enter winter diapause to survive seasonal environmental stresses. The term diapause does not necessarily imply cold hardiness. It is a genetically determined and an endocrine-mediated dormancy that occurs at a specific developmental stage according to the insect species [36]. Examples of egg, larval, pupal, and adult diapause are all well known, but, for most species, the genetic capacity for diapause is restricted to only one of these stages. In diapause, the metabolic rate characteristically drops far below the rates observed in nondiapausing individuals. Food intake is reduced, behavioral changes are frequently observed and need for mitochondrial activity is diminished $[35,36]$.

The activity and integrity of mitochondria without a doubt plays a crucial role in response to and overcoming cold stress. While the complexity of the mitochondrial bioenergetic and signaling network is not yet fully understood, it is increasingly evident that maintenance of the mitochondrial integrity and mitochondrially-derived cellular signaling are critical for cellular homeostasis and survival $[7,37,38]$. They are both the target of cold stress and the central hub that coordinates the cell response to it. Numerous eukaryotes, insects among others, can survive and maintain mitochondrial homeostasis despite the frequent and drastic fluctuations in environmental conditions. Studies on marine ectotherms have shown that oxygen consumption by mitochondria is a good indicator of thermal adaptation and acclimation [39]. However, studies on insects indicate varied effects of cold stress on energy production. Depending on species, strategy of cold resistance and "type of cold stress", that effects might concern changes in ATP level and mitochondria driven energetic homeostasis, which leads consequently to oxidative stress if the production of reactive oxygen species (ROS) overcomes the antioxidative response capabilities of these organelles. Cold stress affects also their morphology, and abundance; as well as mitochondrial and nuclear gene expression pattern, including genes encoding mitochondrial energetic machinery proteins or heat shock proteins (HSP) which act to protect and deal with the effects of stress [40-56]. It is also growingly obvious that the mitochondrial integrity and cellular signaling associated with mitochondria are essential for sustaining the ion and energetic homeostasis of the cell and its survival. As was shown insect mitochondria may also take part in heat dissipation by uncoupling the respiration to protect the cell from harmful effects of cold [54, 57]. If these adaptive mechanisms are inefficient to overcome the cold-stress and the cell damage accumulates the mitochondria commence the processes leading to the programmed cell death pathway as its regulators [58] via apoptosis, to dispose damaged cells [38]. Moreover, what should be kept in mind is that the role of mitochondria in response to cold stress as well as the direction of changes in their activity might vary depending on the species and in what climatic zone they naturally occur, and whether they were acclimated or not to the cold stress. Differences in response to cold stress depending on aforementioned are shown in Table 1. Nevertheless, taking all of that into consideration, we believe that insects can be categorized into three distinct categories implicating mitochondria in cold stress survival. (1) First are historically most studied, chill susceptible insects. Recent studies have shown that it is the ability to maintain active transport that allows these insects to overcome cold stress (reviewed in Overgaard and MacMillan [27], Overgaard et al. [28]). Cold stress will potentially lower the ATP production in aerobic metabolism, thus limiting active transport below passive flux. Hence chill susceptible insects by adaptation or acclimation will ensure mitochondrial function for ATP production. The ability to do this most probably define the limit of cold tolerance. (2) Insects entering the diapause, undergo metabolic depression resulting in resetting of metabolism. Reduction of aerobic ATP production is accompanied by shift in substrate metabolism to allow for accumulation of cryoprotectants. These species will adjust ATP capacity to allow for such shifts. (3) Lastly, there are the "extreme survivals". Insects capable of surviving extreme freezing temperatures-including freezing of the ECM which leads to cell and organelle dehydration.

Since the mitochondrial bioenergetic and signaling network is very complex and much is still to unravel to fully understand it, it is more obvious that maintenance of the mitochondrial function and mitochondrially-derived cellular signaling are critical for cellular homeostasis and survival. This indicates that mitochondria appear to be an interesting target for research regarding cold stress tolerance in insects, and the knowledge about their role in this process can be deeply explored in the future. Hence, this review summarizes the existing knowledge on the role of the cell's "power plants" and their role in insects' resistance to cold stress, indicating new potential research perspectives.

\section{Energetic homeostasis}

A key aspect of the response to cold stress is the modulation of major metabolic pathways responsible for energy metabolism. Oxygen-based respiration offers an enormous advantage for cellular energetics. The production of ATP by complete oxidation of substrate provides more energy in form useful for cells than anaerobic processes. 
Table 1 Changes in genes, energetic parameters of mitochondria and proteins in chill susceptible/chill tolerant or freeze avoiding/ tolerant insects after cold/freeze stress

\begin{tabular}{|c|c|c|c|c|c|}
\hline & & & Chill susceptible/Chill tolerant & & Freeze avoiding/Freeze tolerant \\
\hline \multirow[t]{17}{*}{ Genes } & Acclimated & $\uparrow$ & ATPase (A. colemani) [100] ${ }^{b}$ & $\uparrow \downarrow$ & $\operatorname{COX}\left(\right.$ E. scudderiana) $[35]^{\mathrm{c}}$ \\
\hline & & & & $\uparrow \downarrow$ & 12S rRNA (E. scudderiana) [35] ${ }^{c}$ \\
\hline & & & & $\uparrow$ & HSP60 (D. antiqua) $[103]^{c}$ \\
\hline & & & & $\downarrow$ & HSP60 (L. decemlineata) [104] ${ }^{c}$ \\
\hline & Non-acclimated & $\uparrow$ & COX (D. simulans) [51] & $\uparrow$ & HSP60 (B. antarctica) [53, 105] \\
\hline & & $\uparrow \downarrow$ & HSP60 (D. melanogaster) [106] & $\uparrow$ & HSP60 (F. occidentalis) [107] \\
\hline & & $\uparrow$ & HSP22 (D. melanogaster) [106] & $\uparrow$ & HSP60 (G. daurica) [108] \\
\hline & & $\uparrow$ & HSP23 (D. melanogaster) [106] & $\uparrow$ & HSP60 (M. alternatus) [109] \\
\hline & & $\uparrow$ & mt:ND4 (D. melanogaster) [52] & & \\
\hline & & $\uparrow$ & mt:ND5 (D. melanogaster) [52] & & \\
\hline & & $\uparrow \downarrow$ & mt:COXI (D. melanogaster) [52] & & \\
\hline & & $\uparrow \downarrow$ & mt:COXII (D. melanogaster) [52] & & \\
\hline & & $\uparrow$ & UCP4C (D. melanogaster) [54] & & \\
\hline & & $\uparrow \downarrow$ & HSP23 (D. melanogaster) [110] & & \\
\hline & & $\uparrow$ & HSP23 (S. crassipalpis) [111] & & \\
\hline & & $\uparrow$ & $\operatorname{AccSCO} 2$ (A. cerana) [112] & & \\
\hline & & $\uparrow$ & MUP2 (A. melifera) [55] & & \\
\hline \multirow[t]{18}{*}{ Energetic parameters } & Acclimated & $\bar{\uparrow}$ & ATP (A. diaperinus) $[41]^{\mathrm{b}}$ & $\downarrow$ & cyt. b (G. groenlandicai) [84] \\
\hline & & $\uparrow$ & TCA (A. colemani) [61] & $\downarrow$ & $\begin{array}{l}\text { 3-hydroxyacyl-CoA dehydrogenase } \\
\text { (E. solidaginis) }[79]^{c}\end{array}$ \\
\hline & & $\uparrow$ & citrate (D. melanogaster) [77] & $\downarrow$ & thiolase (E. solidaginis) [79] ${ }^{c}$ \\
\hline & & $\uparrow$ & aconitate (D. melanogaster) [77] & $\downarrow$ & cyt. c (G. groenlandicai) [44] \\
\hline & & $\downarrow$ & ketoglutarate (D. melanogaster) [77] & $\downarrow$ & CS (C. costata) $[76]$ \\
\hline & & $\downarrow$ & succinate (D. melanogaster) [77] & $\downarrow$ & NAD-IDH (E. solidaginis) [47] ${ }^{c}$ \\
\hline & & $\downarrow$ & fumarate (D. melanogaster) [77] & $\downarrow \uparrow$ & state $4\left(C\right.$. costata) $[59]^{c}$ \\
\hline & & $\downarrow$ & OCR (D. melanogaster) [60] & $\uparrow$ & $\operatorname{ATP}(C$. costata $)[59]^{c}$ \\
\hline & & $\uparrow$ & ADP/O (D. melanogaster) [60] & $\uparrow$ & $\begin{array}{l}\text { 3-hydroxyacyl-CoA dehydrogenase } \\
\text { (E. scudderiana) }[79]^{c}\end{array}$ \\
\hline & & $\uparrow \downarrow$ & RCR (D. melanogaster) [60] & $\uparrow$ & thiolase (E. scudderiana) [79] ${ }^{c}$ \\
\hline & & $\downarrow$ & ATP (D. melanogaster) [60] & & \\
\hline & & $\uparrow$ & ATP (S. crassipalpis) [44] $]^{\mathrm{b}}$ & & \\
\hline & Non-acclimated & $\downarrow$ & RCR (G. coquereliana) [89] & $\uparrow$ & NAD-IDH (E. solidaginis) [47] $]^{c}$ \\
\hline & & $\downarrow$ & state 3 (G. coquereliana) [89] & $\downarrow$ & State $4(C$. costata $)[59]^{c}$ \\
\hline & & $\downarrow$ & OCR (D. melanogaster) [60] & $\downarrow$ & GDH (E. scudderiana) $[47]^{c}$ \\
\hline & & $\uparrow \downarrow$ & RCR (D. melanogaster) [60] & & \\
\hline & & $\downarrow$ & ATP (D. melanogaster) [60] & & \\
\hline & & $\downarrow$ & ATP (S. crassipalpis) [44] & & \\
\hline
\end{tabular}


Table 1 (continued)

\begin{tabular}{|c|c|c|c|c|c|}
\hline & & & Chill susceptible/Chill tolerant & & Freeze avoiding/Freeze tolerant \\
\hline \multirow[t]{14}{*}{ Proteins, enzymes } & \multirow[t]{6}{*}{ Acclimated } & $\uparrow$ & Aconitase (A. colemani) [61] & $\downarrow$ & $\operatorname{COX}\left(\right.$ E. solidaginis) $[47]^{c}$ \\
\hline & & $\uparrow$ & Fumarase (A. colemani) [61] & $\uparrow$ & HSP70 (E. solidaginis) $[113]^{\mathrm{b}, \mathrm{c}}$ \\
\hline & & $\uparrow$ & Malate dehydrogenase (A. colemani) [61] & $\uparrow \downarrow$ & HSP70 (E. solidaginis) [113] \\
\hline & & & & $\downarrow$ & $\operatorname{COX}$ (E. scudderiana) $[35,47]^{c}$ \\
\hline & & & & $\uparrow \downarrow$ & SOD (E. solidaginis) [114] ${ }^{c}$ \\
\hline & & & & $\uparrow$ & SOD (E. scudderiana) [114] ${ }^{c}$ \\
\hline & \multirow[t]{8}{*}{ Non-acclimated } & $\downarrow$ & GSHt (A. diaperinus) [115] & & \\
\hline & & $\uparrow$ & UCP (G. coquereliana) [89] & & \\
\hline & & $\uparrow$ & HSP70 (G. coquereliana) [89, 116] & & \\
\hline & & $\uparrow$ & HSP70 (S. exigua) [117] & & \\
\hline & & $\downarrow$ & HSP60 (S. exigua) [117] & & \\
\hline & & $\downarrow \uparrow$ & procaspase-9-like (D. melanogaster) [58] & & \\
\hline & & $\downarrow \uparrow$ & caspase-3-like (D. melanogaster) [58] & & \\
\hline & & $\downarrow$ & Bcl-2 (D. melanogaster) [58] & & \\
\hline
\end{tabular}

The table is divided also into research on insects acclimated to low temperatures (acclimated) and insects not acclimated to low temperatures (non-acclimated). Empty cells in the table indicate that research in this direction has not been conducted and much is still to unravel. As each division would be artificial, we decided to rank insects into species in which cold-induced injury, and death occurs at temperatures above temperature causing extracellular freezing (Chill susceptible/Chill tolerant) and species in which injury is related to ice formation (Freeze avoiding/Freeze tolerant) (for review see Overgaard and MacMillan [27]). Arrows indicate: $\uparrow$ increase/up-regulation, $\downarrow$ decrease/down-regulation, $\uparrow \downarrow$ no change

${ }^{\text {a }}$ Compared to non-acclimated counter partners

${ }^{b}$ FTR or freeze-thaw cycles were used in the studies and not cold-acclimation per se

'Diapausing insects

And because the energy is at the core of all life processes, thus, the cells' ability to produce energy will undergo significant changes depending on cold stress conditions and species-related strategies. The changes will be expressed on different levels from genes through proteins to whole organelles activity and will depend on duration of temperature exposure, temperature altitude, latitude, or/and organismal acclimation to cold stress $[56,59,60]$.

\section{Glycolysis}

Glycolysis is the central pathway for the glucose catabolism in which glucose is converted into pyruvates. Given the importance of nutrient flow through this central metabolic pathway as the source of ATP and production of building blocks for many synthesis reactions, adaptation to thermal stress is expected to modify this pathway. Colinet et al. [61] studied proteins that responded to constant cold or a fluctuating thermal regime (FTR) in a chill susceptible parasitic wasp Aphidius colemani. Proteins that were upregulated in response to FTR included several associated with glycolysis (i.e. aldolase, phosphoglycerate kinase or glyceraldehyde-3-phosphate dehydrogenase. Using pyrosequencing Hahn et al. [62] studied Sarcophaga crassipalpis to identify diapause-responsive genes and compare the gene responses of flesh fly pupae with those of adult diapause in $D$. melanogaster. They found enhanced expression of genes associated with glycolysis and gluconeogenesis (i.e. hexokinase, aldolase, phosphofructokinase) [62, 63]. Later in 2016 Williams et al. [64] also provided evidence for increased reliance on glycolysis in Drosophila melanogaster during cold stress. In another drosophilid, D. suzukii it was found that winter-acclimated individuals also exhibit an up-regulation of glycolysis genes [65]. In diapausing flesh fly $S$. crassipalpis Michaud and Denlinger [66] demonstrated, using metabolomic approach an increase in the glycerol, glucose, alanine, pyruvate-metabolites involved in glycolysis. Together with depression of tricarboxylic acid (TCA) cycle (discussed later on) this could promote the synthesis of glycerol, the major cryoprotectant in insects $[67,68]$. Since glucose carbons may be converted into a number of different compounds through the glycolytic pathway and its branches [66], activation of glycolysis pathway may also promote the increase in the concentration of sugars, polyols or free amino acids which all may act as low-molecular weight cryoprotectants [69-71]. Cryoprotectants lower the melting and supercooling points in chill tolerant and freeze-avoiding insects and 
in freeze-tolerant ones, they lower the proportion of ice [72-74].

Furthermore, as evidenced by glycolytic end product (lactate, alanine) accumulation during freezing, freeze-tolerant species $E$. soldiganis rely on anaerobic metabolism while frozen [50]. This is supported by an observed transient elevation of glucose-6-P levels, suggesting a mobilization of glycogen as fuel, in the early hours after freezing and by continuous accumulation of lactate throughout the long-term freezing exposure [75]. Similar results were obtained in diapausing freezetolerant $C$. costata [76]. In stressed insects (supercooled, freeze-stressed or cryopreserved in liquid nitrogen) were observed symptoms of anaerobic metabolism evidenced by high levels of lactate, succinate, and alanine. Although insects from each treatment showed high level of survival, the larvae preserved in liquid nitrogen showed impaired mitochondrial function demonstrated by the accumulations of glucose and several derivates of the glycolytic pathway side-branches (fructose, myoinositol, sorbitol, and glycine). This suggests that the glycolytic flux is partially diverted from Krebs cycle and production of energy toward accumulation of alanine [76].

\section{Krebs cycle}

Up-regulation of proteins playing crucial roles in TCA cycle was observed in chill susceptible parasitic wasp $A$. colemani [61]. The elevation of Krebs enzymes level was associated with reduced mortality under fluctuating thermal regimes (FTR), when insect exposure to cold was interrupted daily by a transfer to $20^{\circ} \mathrm{C}$ for $2 \mathrm{~h}$, compared to constant low temperature (CLT). Expression of genes encoding aconitase, fumarase and malate dehydrogenase increased during FTR, which may come along with the increase in ATP demand, and thus playing a protective role in maintaining of the energy balance [61]. Metabolite changes were also observed in D. melanogaster larvae under CLT and FTR conditions [77]. Some of the intermediates of TCA, citrate and aconitate, increased, whereas the others: ketoglutarate, succinate, fumarate, and malate decreased suggesting a slowdown of intermediary metabolism, including TCA turnover by a blockade of isocitrate dehydrogenase, which converts isocitrate to ketoglutarate. The changes were faster under CLT as for FTR. Activities of citrate synthase, NAD-isocitrate dehydrogenase and glutamate dehydrogenase were reduced more than $50 \%$ during the winter months in larvae of goldenrod gall insects, freeze-avoiding $E$. scudderiana and freeze-tolerant $E$. solidaginis [47, 48]. In these insect species, a strong decrease of the activity in rate-limiting enzyme for carbohydrate oxidation, pyruvate dehydrogenase complex (PDC) (by around $80 \%$ and $50 \%$, in $E$. scudderiana and E. solidaginis, respectively) was also observed [48]. The activity of citrate synthase (CS), a marker of mitochondrial integrity as well as oxidative capacity, was 1.5 -fold lower in fat body mitochondria of diapausing, compared to active (non-diapausing) larvae of C. costata [76]. Lethally frozen non-diapausing flies showed relatively slight decrease in CS activity but almost total loss of respiration capacity. No changes in CS activity with maintained capacity for oxygen consumption was observed upon freezing either in diapausing insects and non-diapausing fed with proline-supplemented diet [59]. In this last case, proline and other cryoprotective substances may be a part of adaptative changes. It was shown in CS from an Antarctic bacterial strain DS2-3R that the presence of proline residues in $\alpha$ helices changes the flexibility of the enzyme which in turn enables the catalytic activity of the protein at lower temperatures [78]. Perhaps similar properties can be observed in mitochondria of cold-resistant insects, hence crystallographic studies in this filed could be of great value. In the fat body of cold stressed larvae, the silkworm Philosamia ricini increased activity of malate dehydrogenase (MDH) and lactate dehydrogenase (LDH) was consistent with an augmented anaerobic metabolism leading to ethanol, lactate, and alanine as end-products. Reorganization of metabolic activity observed by accumulation of glycolytic products, lactate and alanine during freezing in $E$. solidaginis suggests that anaerobic respiration might be one of the important processes for energy supply over the winter in freeze-tolerant insects [49]. On the other hand, no evidence for disruption of aerobic metabolism (e.g., no lactate accumulation) in freeze-avoiding species $E$. scudderiana was observed.

\section{Fatty acids oxidation}

In contrast to Krebs cycle enzymes, activities of mitochondrial enzymes involved in fatty acid oxidation (3-hydroxyacyl-CoA dehydrogenase, thiolase) increased two- to fourfold over the winter in freeze-avoiding $E$. scudderiana [79], suggesting that aerobic oxidation of lipids in freeze-avoiding insects supports metabolic requirements during the period of low temperatures what indicates for the pivotal role of lipid metabolism in these insect species during cold. Different strategy upon cold was observed in freeze-tolerant $E$. solidaginis, where the activity of enzymes engaged in fatty acid synthesis (malic enzyme) and fatty acids oxidation (carnitine palmityol transferase, 3-hydroxyacyl-dehydrogenase CoA or thiolase) were suppressed [79].

\section{Respiratory chain and oxidative phosphorylation}

Mitochondrial enzymes and proteins of respiratory chain have been shown to be suppressed during the winter 
months in larvae of goldenrod gall insects freeze-avoiding E. scudderiana and freeze-tolerant E. solidaginis [47]. In these species, a decrease of cytochrome c oxidase (COX) activity has been observed. On contrary, chill susceptible fly Drosophila simulans, had higher cytochrome c oxidase activity than their more resistant counterparts [51]. COX, located on the inner mitochondrial membrane, is the terminal electron acceptor in the respiratory chain responsible for the reduction of dioxygen to water and one of the three sites of proton pumping across the inner membrane that creates the electrochemical gradient that drives oxidative phosphorylation $[80,81]$. The defects in the assembly and function of COX are frequent causes of oxidative phosphorylation disorders, which primarily affect organs with high energy demands [82, 83]. In freeze-avoiding E. scuderriana, COX activity decreased about one-third, however at the same time COX1 mRNA transcripts and $12 S$ rRNA levels were unchanged as was evidenced for COX1 DNA content [35]. Ballard et al. [51] observed that in D. simulans variations in mtDNA are associated with differences in cytochrome c oxidase activity. Significantly lower activity of cytochrome c oxidase was determined for flies harboring $s /$ II than $s /$ III mtDNA lines. The differences in mtDNA sequence of fly lines were correlated with a serine replacement in COXII. Those authors showed that flies harboring $s / \mathrm{II}$ mtDNA are more cold-tolerant. Looking at the genes encoding respiratory chain proteins, Camus et al. [52] showed that differences in mtDNA resulted in varied thermal sensitivity of $D$. melanogaster. They found two haplotypes (A1 and B1), depending on whether the insects were from tropical or temperate origins, differing from each other by 15 single nucleotide polymorphisms (SNPs). Flies harboring the B1 haplotype with higher level of gene expression of $m t: N D 4$ and $m t: N D 5$ are superior at withstanding an extreme cold challenge, relative to their A1 counterparts, proving that thermal tolerance phenotypes are directly correlated with the mtDNA sequence. The authors examined the expression patterns of five genes involved in complex I (NADH dehydrogenase) and complex IV (cytochrome oxidase) of the electron transport chain (complex I: $m t: N D 4, m t: N D 5$, complex IV: $m t: C O X I, m t: C O X I I, m t: C O X I I I)$. They found that flies bearing the B1 haplotype had a higher level of gene expression of $m t: N D 4$ and $m t: N D 5$, showing that genetic variation within complex I may affect the thermal tolerance [52] (Fig. 1). Interestingly, Camus et al. [52] did not observe any changes in gene expression of complex IV genes, such as $m t$ :COXI, or $m t: C O X I I$. Moreover, cold stress may affect fat body cytochrome systems, mainly cyt b and cyt $c$ which are crucial in electron transport through the respiratory chain. In frozen and cold-acclimated Gynaephora groenlandica larvae, the content of these cytochromes was slightly reduced compared to control insects [84].

The winter drop-in COX activity, as well as other mitochondrial enzymes, is probably a consequence of the suppression of protein synthesis to reduce the amounts of selected enzymes in mitochondria during cold exposure (slowdown of metabolic activity), or inhibition of enzyme activities, perhaps by reversible controls [80]. Lowered enzyme activities could be also an effect of decreased numbers of mitochondria and suppression of mitochondrial biogenesis. The changes in activity of enzymes and no fluctuations in mtDNA content as well as transcript levels of mitochondrially encoded genes, COX 1 and $12 S$ $r R N A$ may suggest that changes in enzymatic activity of COX are likely mediated via post-translational modification or allosteric regulation [35].

Electron transport through respiratory chain is the main pathway responsible for ATP synthesis, which is required for activities of ion pumps and HSPs or synthesis of cryoprotectants (e.g., glycerol) [41, 85]. Environmental stressors such as cold may disturb energy homeostasis, leading to dysfunction of mitochondrial physiology reflected in decreased coupling and ATP production as well as cellular chilling injuries e.g., membrane alteration and loss of ion or water homeostasis [86-88]. However, the knowledge about the disruption of cellular bioenergetics in insects exposed to low temperature stress, regarding mitochondria is still very scanty. So far, only two studies on mitochondria isolated from coldstressed insects were investigated by Colinet et al. [60] and Chowański et al. [89]. These researchers analyzed mitochondrial condition by determining of oxygen consumption rates (OCRs) in resting state 4 respiration, phosphorylating state 3 (after ADP addition), and the degree of mitochondrial coupling reflected in respiratory control ratio (RCR). This parameter is the most useful measure of isolated mitochondria function and reflects the adjusting the respiration rate (electron transport) to the actual demand for ATP. ADP/O ratio, indicates efficiency of phosphorylation in mitochondria (ATP synthesis) measured as the amount of oxygen uptake stimulated by an addition of a known amount of ADP [90].

Colinet et al. [60] monitored ATP synthesis in D. melanogaster flies exposed to chronic cold stress of $4{ }^{\circ} \mathrm{C}$ in cold-susceptible (CO) and cold-acclimated (CA) phenotypes. In all cases, OCRs and ATP production were significantly affected by the time of cold exposure and decreased with increasing duration of cold stress. RCRs and $\mathrm{ADP} / \mathrm{O}$ ratios were not influenced by the time of cold exposure, but ATP production rates and ADP/O ratio were affected by temperature and were higher when mitochondria were assayed at $25^{\circ} \mathrm{C}$ versus $4{ }^{\circ} \mathrm{C}$. The efficiency of oxidative phosphorylation depended on cold 
acclimation and was higher in mitochondria from CA compared to $\mathrm{CO}$ flies (Fig. 2). Oxygen consumption rates were independent of acclimation treatment, although RCRs were elevated in CA vs. CO flies. Like in other ectotherms [91], higher RCR in CA flies primarily reflected higher mitochondrial oxidative phosphorylation activity (State 3), whereas resting respiration (State 4) remained identical in both phenotypes. On the other hand, respiration measurements in larvae of fly $C$. costata showed that freeze-sensitive (non-diapausing) phenotypes exhibited decreased oxygen consumption rates, whereas mitochondria of freeze-tolerant insects (diapausing, cold acclimated) maintained respiratory capacity during cold stress [59].

The decline in ATP synthesis in control insects after prolonged cold exposure was associated with reduced survival capacity. In contrast, cold-acclimated flies exhibited high survival and maintained higher rates of mitochondrial ATP synthesis and coupling. Concluding, cold acclimation increases rates of ATP, mitochondrial coupling and survival of insects, thereby by maintaining of bioenergetic homeostasis improves their cold tolerance. In chill tolerant tropical cockroach Gromphadorhina coquereliana exposed to $3 \mathrm{~h}$ of cold stress at temperature $4{ }^{\circ} \mathrm{C}$, mitochondria isolated from leg muscle and fat body tissue exhibited decreased RCR, indicating a lower mitochondrial coupling [89]. In the fat body mitochondria, the drop in RCR ratio was accompanied by the decrease in the rate of phosphorylation whereas in muscle mitochondria state 3 phosphorylation remained unchanged. In other chill susceptible insect, tropical lesser mealworm Alphitobius diaperinus thermal regime, constant or fluctuating disturbed ATP supply, however, periodic short pulses of warming (for recovery processes) were enough to restore ATP homeostasis and improve cold survival [41, 92]. Higher levels of ATP may suggest that respiratory function of mitochondrial enzymes in $A$. diaperinus beetle was not critically affected by cold, and ATP synthesis exceeds ATP consumption. The drop in ATP levels was observed in chill tolerant flesh flies Sarcophaga crassipalpis exposed to constant $0{ }^{\circ} \mathrm{C}$ for 20 days and it was associated with high mortality (up to 99\%). However high temperature pulses elevated ATP levels and decreased indirect injury what reflects in higher survival [44].

The disruption of ATP pool in insects exposed to low temperature stress may be explained by changes in enzymatic activity of respiratory chain complexes or/and structure and function of mitochondrial membranes. The alterations in permeability of biological membranes and activity of membrane-bound enzymes, such as $\mathrm{Na}^{+} /$ $\mathrm{K}^{+}$-ATPase under cold exposure was already reported by MacMillan et al. [86], Kostal et al. [87], and Cheslock et al. [93]. Altered permeability of cellular membranes leads to loss of ion/water homeostasis $[94,95]$ and

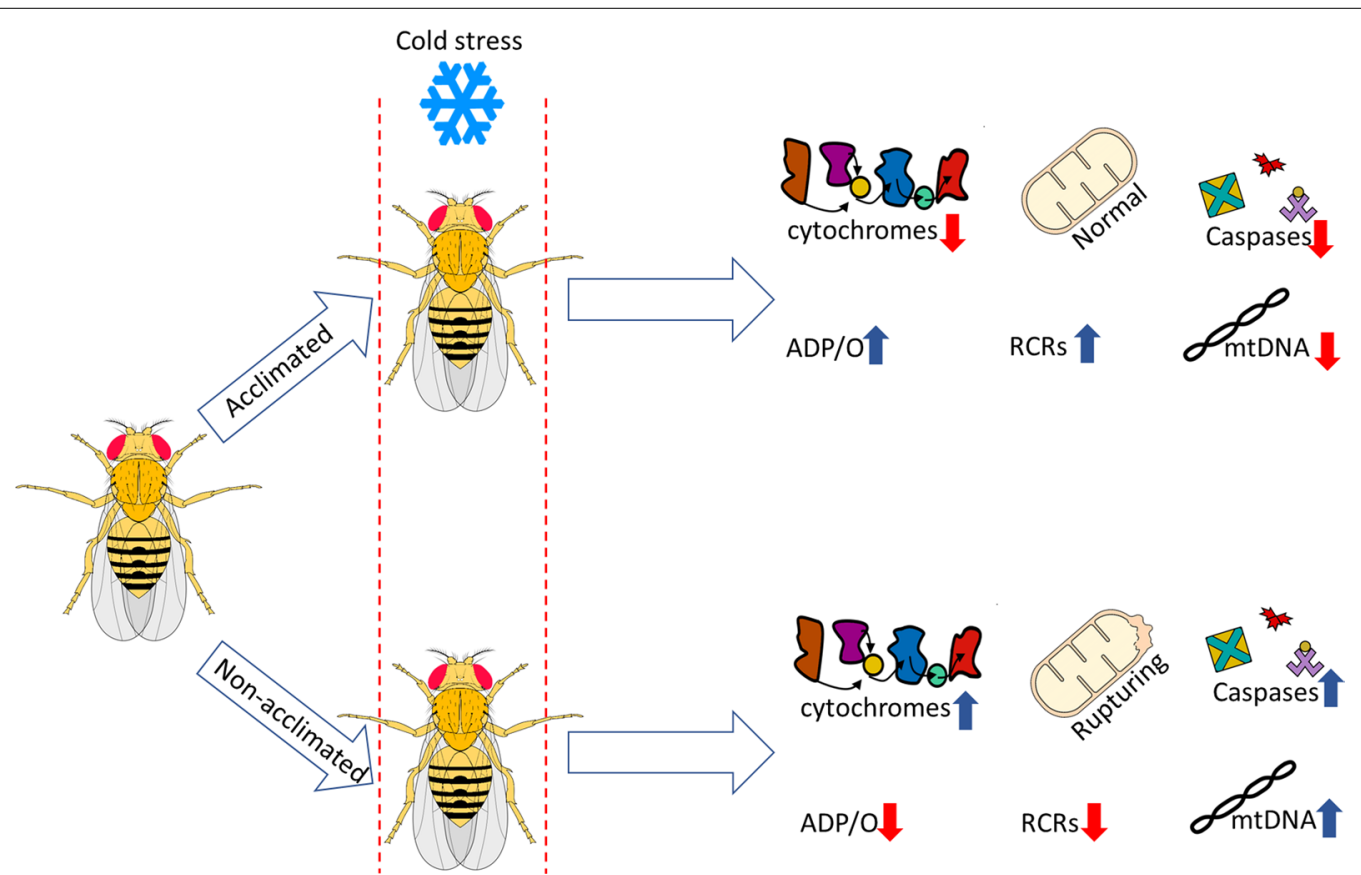

Fig. 2 Scheme representing the effects of cold stress on mitochondria of cold-acclimated and non-acclimated insects. Arrows indicate changes (red-decrease and blue-increase) in particular parameters of insects compared to their counterparts (acclimated vs non-acclimated). ADP/Omitochondrial phosphorylation efficiency, RCR—respiratory control ratio reflecting mitochondrial coupling 
membrane depolarization [96, 97], whereas inhibition of $\mathrm{Na}^{+} / \mathrm{K}^{+}$-ATPase negatively affects mitochondrial bioenergetics [98]. Štětina et al. [59] showed that adaptive changes, such as protection of the inner mitochondrial membrane against permeability transition and mitochondrial swelling in larvae of fly C. costata, could be related to the phenotypic transition to cold acclimation or diapause. Biological membranes, including the inner mitochondrial membrane (IMM) in freeze sensitive insects (non-diapause, warm-acclimated), are susceptible to freezing stress $\left(-5^{\circ} \mathrm{C}\right.$ and $\left.-30^{\circ} \mathrm{C}\right)$, which may cause loss of barrier function, an osmotic influx of cytosolic water into the matrix, and consequently, mitochondrial swelling (Fig. 2). In this case respiration analysis of C. costata fat body mitochondria revealed significant drop in oxygen consumption. In contrast, freeze-tolerant larvae of $C$. costata (either diapause, cold acclimated or non-diapause proline-augmented diet fed) exhibited no mitochondrial swelling and no loss of respiration capacity [59].

Research carried out so far indicates that response to cold stress in insects is tissue- and species-specific. However, some parameters such as disruption of ATP synthesis seem similar either in tropical insects (Gromphadorhina coquereliana) or insects from the temperate zones (D. melanogaster) exposed to low temperature. The important process of insect's acclimation to cold modifies the efficiency of oxidative phosphorylation which is higher in mitochondria from CA compared to $\mathrm{CO}$ insects and finally promotes cold tolerance [41]. Changes due to cold acclimation are reflected not only by maintaining mitochondrial bioenergetics capacity but in the whole organism because of an extensive biological reorganization, almost one-third of the transcriptome and nearly half of the metabolome $[41,99]$. For example, upregulation of ATP-synthase, a multisubunit enzyme of inner mitochondrial membranes responsible for the generation of ATP [100] has been found under FTR in A. colemani.

In some cases, oxidative phosphorylation efficiency can be decreased by activation of uncoupling proteins (UCPs), integral proteins of the inner mitochondrial membrane [101]. UCPs activity is stimulated by free fatty acids (FFA) and inhibited by purine nucleotides (PN). For the first time in insects, UCPs have been functionally characterized in cockroach G. coquereliana [102]. Changes in GcUCP4 activity observed in the fat body and leg muscle of this tropical insect during cold exposure indicate engagement of UCPs in the response to cold stress [89]. It was evidenced the main role of UCPs is diminishing of oxidative stress (described in the Oxidative stress paragraph), although their other function in insects cannot be excluded. In brown adipose tissue of hibernating mammals, uncoupling is the crucial mechanism responsible for heat generation. Similarly, the higher activity of UCP4 in the fat body of G. coquereliana cockroach may indicate the thermogenic role of UCPs (and fat body tissue) in cold stressed insects (Fig. 1). The fat body is a cytological analogue of brown adipose tissue and functional analogue of mammalian liver. The possible involvement of UCP4 in heat generation by uncoupled respiration has been previously suggested by $\mathrm{Da}-\mathrm{Re}$ et al. [54] and Ramirez et al. [55]. In D. melanogaster larvae, by silencing $U c p 4 C$, the authors demonstrated that it is essential for larval development at low temperatures. Ramirez et al. [55] showed that chill susceptible Apis mellifera brood transferred from the control temperature of $36{ }^{\circ} \mathrm{C}$ to colder conditions of $25^{\circ} \mathrm{C}$ strongly increased the transcript level of uncoupling protein (MUP2). In parallel, the ATP level tends to diminish in the cold-stressed brood. These results suggest a potential thermogenic role of MUP2 in honeybee brood reared at low temperatures. In recent study, Ulgherait et al. [57] demonstrated in $D$. melanogaster per $^{01}$ mutants, in which the expression of $U_{c p} 4 B$ and $U_{c p} 4 C$ is constitutively high, that after $1 \mathrm{~h}$ of cold shock at $4{ }^{\circ} \mathrm{C}$, the flies recover significantly quicker than control specimens. Suggesting that $\mathrm{per}^{01}$ mutants may generate more heat than controls. In addition, disruption of $U c p 4 B / C$ in per $^{01}$ flies reverted whole-animal cold shock recovery rates. When $U c p 4 C$ is overexpressed in wild type flies, they show faster cold shock recovery as the per $^{01}$ mutants [57]. This indicates that UCPs take part in cold stress response probably by heat dissipation. However, further studies on plausible thermogenic function of UCPs in insects are required.

Considering above facts, we can distinguish two general strategies which insects evolved to keep energy balance under cold stress conditions. First one, characteristic for freeze tolerant insects is reducing of more oxidative metabolism in favor of less energy-efficient anaerobic respiration. It is accompanied by lowering of COX activity, suppression of fatty acid oxidation (e.g. E. solidaginis) and decrease in CS activity but without losing respiratory capacity (e.g. diapausing C. costata). In turn, chill susceptible (e.g. A. diaperinus) and freeze avoiding insects (e.g. E. sccuderiana) defend against stress in similar manner. Under cold stress insects relaying on this strategy slowdown mitochondrial processes, including oxygen consumption and ATP production, and use aerobic oxidation of fatty acids as a most useful source of energy.

\section{Oxidative stress}

Mitochondria, respiring at normal aerobic conditions, generate reactive oxygen species (ROS). Insects faced with cold stress change their cellular metabolism, which often results in increased accumulation of ROS by mitochondria. Consequently, the mitochondrial antioxidant system during cold stress will be modulated. The dominant ROS, 
superoxide anion $\left(\mathrm{O}_{2}^{--}\right)$is generated mainly from electron leakage from complexes I (exogenous NADH dehydrogenase) and III (ubiquinone, UQ/cytochrome b complex) during electron transport through respiratory chain [118]. $\mathrm{O}_{2}^{-\cdot}$ can be metabolized to hydrogen peroxide $\left(\mathrm{H}_{2} \mathrm{O}_{2}\right)$ by superoxide dismutase (Mn-SOD and $\mathrm{Cu}, \mathrm{Zn}-\mathrm{SOD}$ ), and then transformed via catalase (CAT) or glutathione peroxidase (GPx). Environmental stressors, including cold, can disturb the balance between ROS production and their detoxification leading to oxidative stress. ROS act as signaling molecules within the cell, but their higher concentrations become damaging to molecules such as DNA, proteins or lipids [10]. The chill-susceptible and -tolerant insects will most likely increase the activity of antioxidant machinery to counteract the detrimental effects of ROS accumulation. Jia et al. [112] showed that in Apis cerana, genes encoding syntheses of cytochrome c oxidase (SCOs) are differentially expressed under different environmental cues. In many organisms, SCO proteins are required for $\mathrm{COX}$ activity. During severe cold stress $\left(4{ }^{\circ} \mathrm{C}\right) \mathrm{AccSCO}_{2}$ transcription was induced, which indicates that it may play a role in scavenging superoxide anions generated under cold stress conditions to protect $A$. cerana from ROS-induced damages [112]. The lack of or knockdown of this gene leads to a reduction in the activity of antioxidant enzymes, such as SOD which is typically overexpressed during cold stress [119]. Oxidative stress aroused during cold stress can also lead to increased amounts of SOD and CAT in insects transferred to warmer conditions as was shown in Musca domestica [120] and Locusta migratoria [121], thus, relieving oxidative injury. Lalouette et al. [115] evidenced that cold exposure causes oxidative damage in adult $A$. diaperinus beetles, and that a warm recovery period during fluctuating thermal regimes (FTR) activates the antioxidant mechanism allowing repair of coldinduced damages. Such mechanisms (rewarming pulses) reduce the amount of chill injuries and increase survivability of beetles. Increased severity of cold stress $\left(0-15{ }^{\circ} \mathrm{C}\right)$ during fluctuating thermal regimes caused a decrease in the total glutathione pool (GSHt), whereas SOD levels elevated during the warm recovery period. Similarly, the response of the antioxidant system at the end of the warm period for FTR was sufficient to cope with ROS generation, observed as an increase in GSH:GSSG which is a ratio of reduced to oxidized glutathione illustrating the antioxidant capacity of the cell. [115].

Augmented production of ROS triggers mechanisms leading to reduction of their potentially damaging effect in the cell either by activation of antioxidants [106] or by activation of UCPs. It was evidenced that UCPs crucial role is reducing of free radical generation [122, 123]. In the fat body and muscle mitochondria of G. coquereliana cockroach, activation of UCP4 lowered the level of superoxide anion [102]. Similarly, Alves-Bezerra et al. [124] indicate that UCP4 may be involved in antioxidant defense in Rhodnius prolixus thus protecting cells during oxidative stress aroused during cold exposure. Such mild uncoupling may be a control mechanism of free radical production also, in marine invertebrates [118].

Low temperature or entry into diapause reduces organismal demand on mitochondrial oxygen-based ATP production. In freeze-tolerant species E. solidaginis suppressing of mitochondrial respiration during winter months had beneficial functions for reduction of ROS production by respiratory chain and protecting of mitochondrial membranes during freezing by the concentration of intracellular and intramitochondrial fluids [70]. Joanisse and Storey $[114,125]$ also observed reduced efficiency of antioxidant enzymes in overwintering larvae of this species. Indicating that larvae of E. solidaginis do not face increased challenge from oxidative stress during the numerous freeze-thaw cycles they experience during winter months. Also, freezetolerant $E$. solidaginis seems to lack or have very minimal activity of xanthine oxidase, an enzyme implicated in ROS generation, as it uses oxygen as an oxidizing agent which leads to superoxide formation as its reduction product. The absence of such a conversion in the freeze-tolerant larvae could indicate an adaptive strategy to reduce ROS during oxygen reperfusion during thawing [114]. In another freeze-tolerant insect, Belgica antarctica the freezing causes no significant oxidative damage, while the total antioxidant capacity remains at the constant level when the insects are stressed [126].

On the other hand, increased winter activities of antioxidant enzymes (inter alia SOD, CAT and GST) in freeze-avoiding E. scudderiana suggest that these larvae must defend against detrimental effects of ROS in similar manner as the chill susceptible insects. Even though the metabolism of E. scuderiana is decreased during freezestress, it is still aerobic, which seems to be enough for ROS production at damaging level and increased antioxidant activity to prevent these damages [114].

Therefore, the insects subjected to cold stress rely on two strategies to avoid oxidative stress. It is an increase in the activity of antioxidant enzymes, as is the case with chill-susceptible (in the case of these insects also mild uncoupling by UCP) and freeze-avoiding insects, or they slow down their metabolism, thus reducing the production of ROS and protecting their cells, as evidenced for freeze-tolerant ones.

\section{Heat shock proteins}

In addition to the antioxidant stress system, heat shock proteins (HSPs) can also provide a protective function to stressed cells. Although they are named heat shock proteins, they also take part in response to many other biotic 
and abiotic stresses [127, 128]. HSPs are a part of cell preservation strategy under low temperature and their role in protecting insects against stress, either temperature or desiccation, is studied intensively [106, 129-133]. HSPs are omnipresent in animal cells, some are constitutive and others are inducible in response to environmental stressors such as a cold [134-136]. HSP genes encode a family of highly conserved proteins, which act as chaperones to stabilize and refold denatured proteins, preventing the formation of cytotoxic aggregates [134-136], hence, the expression and activity of heat shock proteins will change during cold stress.

The popularity of HSPs in molecular studies is large due to the high conservation of these genes at the molecular level and therefore, relative ease to clone and evaluate in different species, even where there is limited or no genome data available for that species [106, 129-131]. Animal forms of HSPs are found ubiquitously and can be divided based on their localization in the cell: e.g., endoplasmic reticulum (ER), mitochondrial, and cytosolic forms $[137,138]$. In the mitochondria, HSP70, HSP60, HSP20, and HSP10 proteins have been detected. Some researchers focus their studies on the gene expression profiles of HSP genes while others evaluate the abundance of the proteins. The ideal would be combining both approaches. Hence, in this section italicized names refer to genes (HSP), as opposed to plain type names which refer to research conducted on proteins (HSP).

Lu et al. [107] demonstrated that during cold stress mitochondrial-specific HSP60 from chill-tolerant Frankliniella occidentalis is clearly up-regulated in a timedependent manner. Similarly, frozen larvae of $B$. antarctica tend to have higher expression level of HSP6O [53] and one-third higher during recovery after rapid cold hardening ( $\mathrm{RCH})$ [105]. The slight upregulation of $H S P 60$ can be also observed in Monochamus alternatus, freeze-avoiding beetle [109]. In the Galeruca daurica there is also clear up-regulation of HSP60, the level of which depends on the temperature [108]. On the other hand, the expression pattern of $H S P 60$ does not differ under cold/freezing stress or even tends to be down-regulated in Leptinotarsa decemlineata [104] as it is in other taxa [139]. Similar results were shown in D. melanogaster in which Colinet et al. [106] also did not observe any changes in HSP60 expression pattern during cold stress and recovery period.

Interestingly, they did observe changes in other mitochondrial HSPs genes, HSP22 and HSP23, so called small HSPs (sHSP) [106, 140]. Overexpression of both sHSPs was noted during the recovery after $9 \mathrm{~h}$ of cold stress [106]. The overexpression of sHSP22 was also noted in diapausing, cold-acclimated C. costata larvae, one of the most cold-hardy animals on Earth [76]. As with HSP60, studies on SHSPS showed contradictory results.
In S. crassipalpis, the HSP23 is overexpressed in non-diapausing individuals in response to cold shock $\left(-10{ }^{\circ} \mathrm{C}\right)$ [111]. Whereas during recovery from cold stress $(3 \mathrm{~h}$ at $0{ }^{\circ} \mathrm{C}$ ) Sinclair et al. [110] did not observe any changes in D. melanogaster. Colinet et al. [106] suggested that long exposure to stress is needed to obtain a response from these genes, as they stated "Perhaps, as for Hsp70, it takes several hours under mild cold stress to obtain a response in sHsp genes.". However, they also note that in the same species, Qin et al. [141] reported overexpression of $s H S P s$ during $30 \mathrm{~min}$ of recovery after only $2 \mathrm{~h}$ of cold stress. We believe that the differences in the expression profile of these genes may be caused by the climatic zone of the insect's origin. Colinet et al. [106] conducted their studies on flies from a rather tropical zone (Innisfail, Australian east coast) whereas Sinclair et al. [110] from temperate (Terhune, New Jersey, USA). Hence, authors working in the future on this topic should consider the origins of the insects as well as possible differential expression during cold stress and recovery from it. Nevertheless, mitochondrial (s)HSPs are essential for insect survival as the RNAi experiments showed that silencing of HSP22 and HSP23 reduces insect survival during cold stress [142]. Additionally, HSP22 protein takes part in protecting cells against oxidative injuries [143]. The activation of these molecules plays a significant role in the secretion of signaling molecules or the induction of tissue regeneration [144]. Therefore, the proper activity of these genes can be very important not so much during cold stress, but during cold stress recovery, and future.

Mitochondrial HSP70 plays a central role in mitochondrial biogenesis. Zhang et al. [113] showed that a member of this family increases its abundance during winter months in E. solidaginis. Laboratory induced freezing of the insect (larvae shifted acutely from $3{ }^{\circ} \mathrm{C}$ down to $-16{ }^{\circ} \mathrm{C}$ and frozen for $24 \mathrm{~h}$ ), and the laboratory cold treatment $\left(3{ }^{\circ} \mathrm{C}\right.$ exposed for $\left.24 \mathrm{~h}\right)$ did not cause changes in protein abundance. Only freeze-thaw treatment (similar to environmental conditions) caused substantial increase, which provided enhancement of mitochondrial chaperone activity comparable to that seen for the cytoplasmic and endoplasmic reticulum [113]. Many authors focus their research on HSP70 protein, however they do not discriminate between the cytosolic and mitochondrial fractions of these proteins, most often measuring their entire pool in the cell. The studies on mitochondrially-specific HSP70 during cold stress is limited. Hence, the studies on different fractions are a promising line of research, as the function of HSPs may be different during recovery time (neutralization of damages after cold stress) and during stress (protection against damages during cold stress) as well as due to their cellular localization. 
The HSP60 family of proteins that is specific for mitochondrial localization possess a characteristic (GGM) n repeat motif $[139,145]$. HSP60 is known to chaperone nascent polypeptides for their transport from the cytoplasm to the mitochondrial matrix in conjunction with HSP10 that also resides in the mitochondria [146]. Moreover, to its classical chaperone function, mitochondrial HSP60 is critically implicated in the replication and transmission of mitochondrial DNA [147]. Compared to the upregulation of HSP in E. solidaginis, mitochondrial HSP60 protein is strongly suppressed over the winter months [113]. It is worth mentioning that this pattern parallels lowered activities of many mitochondrial enzymes e.g., citrate synthase, glutamate dehydrogenase, NAD-isocitrate dehydrogenase, malic enzyme, cytochrome c oxidase and enzymes of fatty acid oxidation that are reduced by $50-65 \%$ during cold exposure in E. solidaginis [35, 47, 79]. HSP60 can also enhance cold hardiness and promote membrane stability. In Delia anti$q u a$ it contributes to the enhancement of cold hardiness through repression of the depolymerization of actin filaments at low temperatures [103].

As mentioned above HSP10 is a co-chaperone and work in conjunction with HSP60, exerting its biological functions in diverse conditions [148]. HSP60 and HSP10 form a folding cage through their rings and HSP60HSP10 complex may accelerate polypeptide folding, denatured protein refolding, and misfolded protein correcting [149-151]. Data on the HSP10 activity in insects is scarce. Understanding the gene expression patterns and its biological interactions with HSP60 and HSP70 would bring us closer to understanding the role of this protein/s in mechanism responsible for cold stress tolerance in insects.

The research on mitochondrial fraction of different HSPs forms is limited, however, the picture emerging from the available studies indicates that, whatever the type of strategy insects use to survive the cold/freeze stress, there is an up-regulation of $(s) H S P s /(\mathrm{s}) \mathrm{HSPs}$.

\section{Apoptosis}

Mitochondria are crucial for cells and organisms surviving not only because of being an energetic center, but also as regulators of programmed cell death in which they take a significant part [152]. Cold stress is a generator of oxidative stress and affects mitochondria disrupting their functioning, thus it might be supposed, that cold stress is associated with induction of apoptosis via mitochondrial pathways. Mitochondria can switch from the adaptive response to cell death due to energy deficiency and/or the overwhelming mitochondrial or cellular damage $[37,38]$. Nevertheless, the knowledge about apoptosis induced by cold stress, especially via mitochondrial pathway, in insect is very scanty. There are only a few papers showing connection between cold, mitochondria and apoptosis. In 2007, Yi et al. [58] showed that cold stress increases the number of apoptotic cells in flight muscles of chill susceptible flies, D. melanogaster, which were not cold acclimated. On the other hand, these authors showed that $\mathrm{RCH}$ protects the cells against apoptosis and observed that in insects, which were acclimated to a low temperature before cold or freezing treatment, the apoptotic rate was significantly lower than in the group without acclimation. The researchers also analyzed the level of different apoptotic factors. They noticed that two caspases (procaspase-9-like and active caspase-3-like) were present in both groups-cold-acclimated and non-acclimated, but they were least abundant in the first group. Moreover, the apoptotic inhibitor Bcl-2 was down-regulated in cold-shocked group compared to the control and $\mathrm{RCH}$ groups [58]. The participation of mitochondria in apoptosis might be associated with mitochondria swelling, and role of mitochondria in the balance of cellular calcium level. Above mentioned are suggested by results obtained by Štětina et al. [59] and Bayley et al. [153]. Štětina et al. [59] showed that in freeze-sensitive (nondiapause) phenotype larvae of fly, C. costata, the mitochondria undergo swelling in responses to freezing stress what was not observed in freeze-tolerant (diapausing, cold-acclimated) phenotype. Interestingly, the freezinginduced mitochondrial swelling was abolished by feeding freeze-sensitive larvae on a proline-augmented diet, thus, the authors suggest the stabilizing role of proline against mitochondria swelling. Regrettably, they did not analyze the occurrence of apoptosis in studied insects [59]. While Bayley et al. [153] showed that cold induces an excessive $\mathrm{Ca}^{2+}$ influx, increasing the intracellular calcium level in muscle cells of the tropical (chill-susceptible) migratory locust L. migratoria. That may induce $\mathrm{Ca}^{2+}$-mediated necrosis/apoptosis probably also including mitochondria swelling. Kumarswamy et al. [154] showed that mitochondrial $\mathrm{Ca}^{2+}$ overload occurs in apoptotic insect $\mathrm{Sf} 9$ cells treated with actinomycin-D. Moreover, the research conducted in $D$. melanogaster has shown that regulation of HSP60, a mitochondrial chaperon responsible for maintaining homeostasis of mitochondrial proteins [155] is essential for caspase-dependent apoptosis [156], while the sHSPs prevent this pathway [157]. Tight regulation of apoptosis is essential for survival as the stimulated activity of caspases is not solely the indicator of apoptosis but besides, it demonstrates nonapoptotic functions i.e., control of a cell shape, cell migration or proliferation.

The data concerning apoptosis induced by cold stress as well as the role of mitochondria in it are very poor. Nevertheless, they support guess that mitochondria play 
an important role in protection against cold stress as participants and also executors of programed cell death.

\section{Morphology}

In consequence to the abovementioned phenomena, it seems obvious that mitochondrial morphology must undergo significant alterations. Mitochondria are dynamic organelles composed of double membranes $[158,159]$. The shape, size and/or the number of mitochondria is extremely plastic and can be modulated by physiological conditions as well as environmental cues [160-162]. In plants and animals such as cold-bodied fish, it is well established that low temperature affects the shape and the number of these organelles and their velocity within the cell [163-165]. However, the number of studies on the effect of low and freezing temperature on morphology and number of insect mitochondria is scarce and to our knowledge, only a handful of researchers have touched this topic. Available data suggest that in insects (freeze-tolerant) the number of mitochondria is reduced $[35,84,166]$. For G. groenlandica, drop of temperature down to $0{ }^{\circ} \mathrm{C}$ is a signal for starting the dormancy period. They break down mitochondria in response to cold-acclimation (i.e., their number decreases, and they degenerate), and enter diapause as a strategy to conserve energy when the temperature drops down $[84,167]$.

Another typical symptom in response to stressors is mitochondrial swelling which in consequence leads to dilution of the matrix and finally to rupture of the outer membrane [168, 169] (Fig. 1). Lee et al. [170] showed that in Malpighian tubules of freeze-tolerant E. solidaginis larvae subjected to lethal for them temperature of $-55{ }^{\circ} \mathrm{C}$, mitochondria had been swollen and round-shaped in contrast to individuals subjected to sub-lethal freezing at $-22{ }^{\circ} \mathrm{C}$, whose mitochondria had remained rod-shaped. In the same species, E. solidaginis and G. groenlandica, Levin et al. [166] observed a reduction in the mitochondrial activity in larvae collected in colder seasons (i.e. cold-acclimated individuals), in comparison with the insects collected in summer, which can be the effect of the drop in the number of mitochondria expressed by a decrease in the amount of mtDNA. Štětina et al. [59] tested the effects of freezing stress on mitochondria of $C$. costata larvae. Although in acclimated (diapausing) insects the freezing stress had no effect on the number of mitochondria-contrary to the non-acclimated (non-diapausing) individuals-after acclimation mitochondria were not evenly distributed within the cell, and two sub-populations were distinguished-one located around the nucleus and the other close to the cell periphery. In the same study, the authors observed (although, statistically not significant) "certain tendency" to swelling of mitochondria. Exposing non-acclimated individuals of C. costata to freeze stress resulted in ca. $65 \%$ mortality, caused enlargement and swelling of mitochondria with dilution of electron-dense material in the matrix [59]. The authors presented electronograms of mitochondria obtained from warm-acclimated and coldacclimated $C$. costata larvae. The cold-acclimated larvae possessed mitochondria with clearly visible, more numerous cristae. That suggests more intensive oxidative metabolism. The enlarged mitochondria, the loss of matrix density and altered cristae may result from oxidative stress, which in turn can be the effect of low temperature.

The results of our preliminary electron microscopic research on cold-stressed G. coquereliana, and applied stereological observations (unpublished) suggest that low temperatures $\left(4{ }^{\circ} \mathrm{C}\right)$ may cause fine ultrastructural changes of the fat body, including mitochondria. Although we did not note significant alterations of the shape or electron density of mitochondria, there was a slight growth of the ratio of the surface of the inner membrane to the outer one, as shown in stereological calculations. This indicates the increased surface of the inner membranes within mitochondria, and, in consequence, intensification of the energy metabolism within mitochondria of the fat body of the coldexposed insects. Next, the number of glycogen granules within the cytoplasm slightly decreased in the fat body of stressed organisms. This is consistent with our earlier results where short cold stress $\left(3 \mathrm{~h}, 4{ }^{\circ} \mathrm{C}\right)$, as well as repeated exposure to low temperature $\left(3 \times 8 \mathrm{~h}, 4{ }^{\circ} \mathrm{C}\right)$, lowered the glycogen content in fat body tissue [89, 116]. Fat body plays a crucial role in controlling of storage and utilization of energy reserves in insects. The primary source of energy are lipids [171]. Therefore, altered level of glycogen may appear when the stress is significant. Perhaps, the time of exposure to stress plays a crucial role in the process. Glycogen, in turn, plays important role in the synthesis of sugar alcohols, trehalose and glucose which are mobilized during adaptation to cold $[69,172,173]$. At the same time, glycogen level decreases [174]. Next, glycogen and glucose are crucial substrates for synthesis of glycerol, which is one of the important cryoprotectants [74]. Hence, one may conclude that energetic metabolism plays an important role in response to low temperatures, in insects, and in consequence, significantly affects mitochondrial structure.

\section{Future directions}

Mitochondria play a key role in energy supplying and conversion in all living organisms, including insects. Their activity as well as other cellular organelles and 
biochemical processes depends on many environmental factors, among them temperature is one of the most important. We know that cold stress may trigger mechanisms leading to decline of mitochondrial oxidative capacity, loss of metabolic homeostasis, depletion of energy substrates, oxidative damage and in consequence cellular injury. On the other hand, mitochondria are capable to counteract and adjust to the effects of cold stress to maintain energetic homeostasis and this response may be varied at different cellular levels (gene expression, protein level, activity of enzymes) and depends on climatic zone or adaptation of insects to cold stress.

Some questions arise, how collapsing of mitochondrial function, especially their capacity for ATP production evoked by low temperature stress is related to thermal limits of insects at cellular and organismal level. How is the correlation between these processes and growth and development of insects under the cold stress and fluctuating temperature conditions? At the time of climate changing, maintaining of energy homeostasis may be crucial for survival of insect species and their distribution at different latitudes. Considering that electron transport system (ETS) is responsible for $80-90 \%$ oxidative phosphorylation capacity, it seems crucial to explore, how mitochondria provide energetic requirements in the cells, and this way enable survival of insects during cold stress conditions.

Another interesting venue for the future research is analyzing cellular mechanisms which function depends on the access of ATP such as $\mathrm{Na}^{+} / \mathrm{K}^{+}$-ATPase, protein pump in cellular membrane powered by ATP which allows the cell to maintain mineral-water homeostasis. Poorly understood is the role of insect mitochondria in controlling of calcium homeostasis in the cell and their involvement in apoptotic processes caused by cold. It seems interesting also to elucidate the potential thermogenic role of UCP in insects exposed to low temperature stress, and the engagement of these proteins and other mechanisms in redox homeostasis, which is an important part of stress tolerance in insects. It would be also interesting to make relationship between mitochondrial response and cellular transduction pathways in cold-tolerant and cold-sensitive insects from different geographical zones, by using common methods and experimental conditions. Data obtained so far are ambiguous and do not allow us to draw the final conclusions giving researchers the big task of resolving these issues in the future.

\section{Abbreviations}

TCA: Tricarboxylic acid cycle; FTR: Fluctuating thermal regime; CLT: Constant low temperature; PDC: Pyruvate dehydrogenase complex; SCP: Supercooling point; CS: Citrate synthase; MDH: Malate dehydrogenase; LDH: Lactate dehydrogenase; COX: Cytochrome c oxidase; mtDNA: Mitochondrial DNA; HSP: Heat shock protein; RCR: Respiratory control ratio; OCR: Oxygen consumption ratio; CO: Cold-susceptible; CA: Cold-acclimated; IMM: Inner mitochondrial membrane; UCP: Uncoupling protein; ADP/O: Mitochondrial phosphorylation efficiency; FFA: Free fatty acids; PN: Purine nucleotides; ROS: Reactive oxygen species; CAT: Catalase; SOD: Superoxide dismutase; GP: Glutathione peroxidase; SCO: Synthase of cytochrome c oxidase; RCH: Rapid cold hardening; ETS: Electron transport system.

\section{Acknowledgements}

We would like to thank prof. Johannes Overgaard and Dr Lisa Jørgensen for their review and constructive comments on the first version of this manuscript.

\section{Authors' contributions}

All the authors are responsible for the general idea of the manuscript and text editing. JL coordinated the Introduction, Glycolysis, Oxidative stress and Heat shock protein sections, MS coordinated Energetic homeostasis and Future directions sections, SC coordinated Apoptosis section and ZA coordinated Morphology section. SCh prepared Fig. 1, JL prepared Fig. 1 and 2, and Table 1. All authors have read and agreed to the published version of the manuscript. All authors read and approved the final manuscript.

\section{Funding}

This work was partially supported by the National Science Centre, Poland, by Grant Nos. 2017/24/C/NZ4/00228 and 2019/35/D/NZ4/02731.

Availability of data and materials

Not applicable.

\section{Declarations}

Ethics approval and consent to participate

Not applicable.

Consent for publication

Not applicable.

\section{Competing interests}

The authors declare that they have no competing interests.

\section{Author details}

${ }^{1}$ Department of Animal Physiology and Developmental Biology, Institute of Experimental Biology, Faculty of Biology, Adam Mickiewicz University, Poznan, Poland. ${ }^{2}$ Laboratory of Electron and Confocal Microscopy, Faculty of Biology, Adam Mickiewicz University, Poznan, Poland.

Received: 6 July 2021 Accepted: 13 December 2021

Published online: 06 January 2022

References

1. Margulis L, Sagan D. Origins of sex: three billion years of genetic recombination. New Haven: Yale University Press; 1986.

2. Lane N. Mitonuclear match: optimizing fitness and fertility over generations drives ageing within generations. BioEssays. 2011;33:860-9.

3. Havird JC, Hall MD, Dowling DK. The evolution of sex: A new hypothesis based on mitochondrial mutational erosion: Mitochondrial mutational erosion in ancestral eukaryotes would favor the evolution of sex, harnessing nuclear recombination to optimize compensatory nuclear coadaptation. BioEssays. 2015:37:951-8.

4. Hill GE. Mitonuclear Ecology. Mol Biol Evol. 2015;32:1917-27.

5. Breda CNdS, Davanzo GG, Basso PJ, Saraiva Câmara NO, Moraes-Vieira PMM. Mitochondria as central hub of the immune system. Redox Biology. 2019;26:101255.

6. Hamanaka RB, Chandel NS. Mitochondrial reactive oxygen species regulate cellular signaling and dictate biological outcomes. Trends Biochem Sci. 2010;35:505-13. 
7. Lane N. Power, sex, suicide: mitochondria and the meaning of life. Second edition. edn. Oxford: Oxford University Press; 2018.

8. Monlun M, Hyernard C, Blanco P, Lartigue L, Faustin B. Mitochondria as molecular platforms integrating multiple innate immune signalings. J Mol Biol. 2017:429:1-13.

9. Hood WR, Austad SN, Bize P, Jimenez AG, Montooth KL, Schulte PM, et al. The mitochondrial contribution to animal performance, adaptation, and life-history variation. Integr Comp Biol. 2018;58:480-5.

10. Sokolova I. Mitochondrial adaptations to variable environments and their role in animals' stress tolerance. Integr Comp Biol. 2018;58:519-31.

11. Gillooly JF, Brown JH, West GB, Savage VM, Charnov EL. Effects of size and temperature on metabolic rate. Science. 2001;293:2248-51.

12. Basha $E, O^{\prime}$ Neill $H$, Vierling E. Small heat shock proteins and alphacrystallins: dynamic proteins with flexible functions. Trends Biochem Sci. 2012;37:106-17.

13. Pietri JE, Tiffany $C$, Liang D. Disruption of the microbiota affects physiological and evolutionary aspects of insecticide resistance in the German cockroach, an important urban pest. PLoS ONE. 2018;13:e0207985-e0207985.

14. McCue MD, De Los SR. Upper thermal limits of insects are not the result of insufficient oxygen delivery. Physiol Biochem Zool. 2013;86:257-65.

15. Harrison JF, Manoucheh M, Klok CJ, Campbell JB. Temperature and the ventilatory response to hypoxia in Gromphadorhina portentosa (Blattodea: Blaberidae). Environ Entomol. 2016;45:479-83.

16. Terblanche JS, Hoffmann AA, Mitchell KA, Rako L, le Roux PC, Chown $\mathrm{SL}$. Ecologically relevant measures of tolerance to potentially lethal temperatures. J Exp Biol. 2011:214:3713-25.

17. Terblanche JS, Karsten M, Mitchell KA, Barton MG, Gibert P: Physiological variation of insects in agricultural landscapes: potential impacts of climate change. In Climate change and insect pests. Volume 6. Edited by Bjorkman C, Niemela P; 2015: 92

18. Bowler K, Terblanche JS. Insect thermal tolerance: what is the role of ontogeny, ageing and senescence? Biol Rev Camb Philos Soc. 2008;83:339-55.

19. Lubawy J, Daburon V, Chowański S, Słocińska M, Colinet H. Thermal stress causes DNA damage and mortality in a tropical insect. J Exp Biol. 2019;222.

20. Lubawy J, Słocińska M. Characterization of Gromphadorhina coquereliana hemolymph under cold stress. Sci Rep. 2020;10:12076.

21. Lubawy J, Urbański A, Colinet H, Pfluger HJ, Marciniak P. Role of the insect neuroendocrine system in the response to cold stress. Front Physiol. 2020;11:376

22. Hoffmann AA, Sørensen JG, Loeschcke V. Adaptation of Drosophila to temperature extremes: bringing together quantitative and molecular approaches. J Therm Biol. 2003;28:175-216.

23. Angilletta Jr MJ, Angilletta MJ: Thermal adaptation: a theoretical and empirical synthesis. Oxford University Press; 2009.

24. Colinet $H$, Hoffmann AA. Comparing phenotypic effects and molecular correlates of developmental, gradual and rapid cold acclimation responses in Drosophila melanogaster. Funct Ecol. 2012;26:84-93.

25. Colinet H, Overgaard J, Com E, Sorensen JG. Proteomic profiling of thermal acclimation in Drosophila melanogaster. Insect Biochem Mol Biol. 2013:43:352-65.

26. Gerber L, Kresse J-C, Šimek P, Berková P, Overgaard J. Cold acclimation preserves hindgut reabsorption capacity at low temperature in a chillsusceptible insect, Locusta migratoria. Comparative Biochemistry and Physiology Part A: Molecular \& Integrative Physiology. 2021;252:110850.

27. Overgaard J, MacMillan HA. The Integrative Physiology of Insect Chill Tolerance. Annu Rev Physiol. 2017;79:187-208.

28. Overgaard J, Gerber L, Andersen MK. Osmoregulatory capacity at low temperature is critical for insect cold tolerance. Curr Opin Insect Sci. 2021:47:38-45.

29. Sinclair BJ, Coello Alvarado LE, Ferguson LV. An invitation to measure insect cold tolerance: Methods, approaches, and workflow. J Therm Biol. 2015;53:180-97.

30. Boardman L, Grout TG, Terblanche JS. False codling moth Thaumatotibia leucotreta (Lepidoptera, Tortricidae) larvae are chill-susceptible. Insect Science. 2012;19:315-28.

31. Hayward SA, Manso B, Cossins AR. Molecular basis of chill resistance adaptations in poikilothermic animals. J Exp Biol. 2014:217:6-15.
32. Bale JS. Insect cold hardiness: A matter of life and death. EJE. 1996;93:369-82.

33. Crosthwaite JC, Sobek S, Lyons DB, Bernards MA, Sinclair BJ. The overwintering physiology of the emerald ash borer, Agrilus planipennis fairmaire (coleoptera: buprestidae). J Insect Physiol. 2011:57:166-73.

34. Koštál V, Zahradníčková H, Šimek P. Hyperprolinemic larvae of the drosophilid fly, Chymomyza costata, survive cryopreservation in liquid nitrogen. Proc Natl Acad Sci. 2011;108:13041-6.

35. McMullen DC, Storey KB. Mitochondria of cold hardy insects: responses to cold and hypoxia assessed at enzymatic, mRNA and DNA levels. Insect Biochem Mol Biol. 2008;38:367-73.

36. Denlinger DL: Relationship between Cold Hardiness and Diapause. In Insects at Low Temperature. Edited by Lee RE, Denlinger DL. Boston, MA: Springer US; 1991: 174-198

37. Bohovych I, Khalimonchuk O. Sending out an SOS: mitochondria as a signaling hub. Front Cell Dev Biol. 2016:4:109.

38. Vakifahmetoglu-Norberg H, Ouchida AT, Norberg E. The role of mitochondria in metabolism and cell death. Biochem Biophys Res Commun. 2017;482:426-31.

39. Dahlhoff E, Somero G. Effects of temperature on mitochondria from abalone (genus Haliotis): adaptive plasticity and its limits. J Exp Biol. 1993;185:151-68.

40. Pullin A, Bale J. Cause and effects of pre-freeze mortality in aphids. CryoLetters. 1988;9:101-13.

41. Colinet H. Disruption of ATP homeostasis during chronic cold stress and recovery in the chill susceptible beetle (Alphitobius diaperinus). Comp Biochem Physiol A Mol Integr Physiol. 2011;160:63-7.

42. El-Shesheny I, Hijaz F, El-Hawary I, Mesbah I, Killiny N. Impact of different temperatures on survival and energy metabolism in the Asian citrus psyllid, Diaphorina citri Kuwayama. Comp Biochem Physiol A Mol Integr Physiol. 2016:192:28-37.

43. Macmillan HA, Williams CM, Staples JF, Sinclair BJ. Metabolism and energy supply below the critical thermal minimum of a chill-susceptible insect. J Exp Biol. 2012;215:1366-72.

44. Dollo VH, Yi SX, Lee RE Jr. High temperature pulses decrease indirect chilling injury and elevate ATP levels in the flesh fly, Sarcophaga crassipalpis. Cryobiology. 2010;60:351-3.

45. Koštál V, Vambera J, Bastl J. On the nature of pre-freeze mortality in insects: water balance, ion homeostasis and energy charge in the adults of Pyrrhocoris apterus. J Exp Biol. 2004;207:1509-21.

46. Pullin A, Fontaine $X$, Bale J. Application of 31P-NMR to the study of prefreeze mortality in aphids. Cryo-Letters. 1990:11:127-36.

47. Joanisse DR, Storey KB. Mitochondrial enzymes during overwintering in 2 species of cold-hardy gall insects. Insect Biochem Mol Biol. 1994;24:145-50.

48. Rider MH, Hussain N, Dilworth SM, Storey JM, Storey KB. AMP-activated protein kinase and metabolic regulation in cold-hardy insects. J Insect Physiol. 2011;57:1453-62.

49. Singh A, Jaiswal SK, Sharma B. Low temperature induced stress and biomolecular imbalances in insects with special reference to silkworms. Journal of Biochemistry Research. 2013;1:26-35.

50. Storey JM, Storey KB. Freezing and cellular metabolism in the gall fly larva, Eurosta solidaginis. J Comp Physiol B. 1985:155:333-7.

51. Ballard JWO, Melvin RG, Katewa SD, Maas K. Mitochondrial dna variation is associated with measurable differences in life-history traits and mitochondrial metabolism in Drosophila simulans. Evolution. 2007;61:1735-47.

52. Camus MF, Wolff JN, Sgro CM, Dowling DK. Experimental support that natural selection has shaped the latitudinal distribution of mitochondrial haplotypes in Australian Drosophila melanogaster. Mol Biol Evol. 2017;34:2600-12.

53. Teets NM, Dalrymple EG, Hillis MH, Gantz JD, Spacht DE, Lee RE, et al. Changes in energy reserves and gene expression elicited by freezing and supercooling in the Antarctic midge, Belgica antarctica. Insects. 2020;11:18

54. Da-Re C, De Pitta C, Zordan MA, Teza G, Nestola F, Zeviani M, et al. UCP4C mediates uncoupled respiration in larvae of Drosophila melanogaster. EMBO Rep. 2014;15:586-91.

55. Ramirez L, Luna F, Mucci CA, Lamattina L. Fast weight recovery, metabolic rate adjustment and gene-expression regulation define responses of cold-stressed honey bee brood. J Insect Physiol. 2021;128:104178. 
56. Colinet H, Rinehart JP, Yocum GD, Greenlee KJ. Mechanisms underpinning the beneficial effects of fluctuating thermal regimes in insect cold tolerance. J Exp Biol. 2018;221:jeb164806.

57. Ulgherait M, Chen A, McAllister SF, Kim HX, Delventhal R, Wayne CR, et al. Circadian regulation of mitochondrial uncoupling and lifespan. Nat Commun. 2020;11:1927

58. Yi SX, Moore CW, Lee RE Jr. Rapid cold-hardening protects Drosophila melanogaster from cold-induced apoptosis. Apoptosis. 2007:12:1183-93.

59. Štětina T, Des Marteaux LE, Koštál V. Insect mitochondria as targets of freezing-induced injury. Proc R Soc B-Biol Sci. 2020;287:2161.

60. Colinet H, Renault D, Roussel D. Cold acclimation allows Drosophila flies to maintain mitochondrial functioning under cold stress. Insect Biochem Mol Biol. 2017;80:52-60.

61. Colinet H, An Nguyen TT, Cloutier C, Michaud D, Hance T. Proteomic profiling of a parasitic wasp exposed to constant and fluctuating cold exposure. Insect Biochem Mol Biol. 2007;37:1177-88.

62. Hahn DA, Ragland GJ, Shoemaker DD, Denlinger DL. Gene discovery using massively parallel pyrosequencing to develop ESTs for the flesh fly Sarcophaga crassipalpis. BMC Genomics. 2009;10:234.

63. Ragland GJ, Denlinger DL, Hahn DA. Mechanisms of suspended animation are revealed by transcript profiling of diapause in the flesh fly. Proc Natl Acad Sci USA. 2010;107:14909-14

64. Williams CM, McCue MD, Sunny NE, Szejner-Sigal A, Morgan TJ, Allison DB, et al. Cold adaptation increases rates of nutrient flow and metabolic plasticity during cold exposure in Drosophila melanogaster. Proceedings Biological sciences. 2016:283:20161317.

65. Shearer PW, West JD, Walton VM, Brown PH, Svetec N, Chiu JC. Seasonal cues induce phenotypic plasticity of Drosophila suzukii to enhance winter survival. BMC Ecol. 2016;16:11

66. Michaud MR, Denlinger DL. Shifts in the carbohydrate, polyol, and amino acid pools during rapid cold-hardening and diapause-associated cold-hardening in flesh flies (Sarcophaga crassipalpis): a metabolomic comparison. J Comp Physiol B. 2007;177:753-63.

67. Yoder JA, Benoit JB, Denlinger DL, Rivers DB. Stress-induced accumulation of glycerol in the flesh fly, Sarcophaga bullata: Evidence indicating anti-desiccant and cryoprotectant functions of this polyol and a role for the brain in coordinating the response. J Insect Physiol. 2006:52:202-14.

68. Sømme L. Supercooling and winter survival in terrestrial arthropods. Comp Biochem Physiol A Physiol. 1982;73:519-43.

69. Overgaard J, Malmendal A, Sorensen JG, Bundy JG, Loeschcke V, Nielsen NC, et al. Metabolomic profiling of rapid cold hardening and cold shock in Drosophila melanogaster. J Insect Physiol. 2007;53:1218-32.

70. Storey KB, Storey JM. Insect cold hardiness: metabolic, gene, and protein adaptation. Can J Zool. 2012;90:456-75.

71. Denlinger DL. Temperature sensitivity in insects and application. Boca Raton: CRC Press; 1998.

72. Storey KB, Storey JM. Molecular Physiology of Freeze Tolerance in Vertebrates. Physiol Rev. 2017:97:623-65.

73. Zachariassen KE. Physiology of cold tolerance in insects. Physiol Rev. 1985:65:799-832.

74. Storey KB, Storey JM. Biochemistry of cryoprotectants. In: Lee RE, Denlinger DL, editors. Insects at low temperature. Boston: Springer; 1991. p. 64-93.

75. Ballantyne JS, Storey KB. Characterization of mitochondria isolated from the freezing-tolerant larvae of the goldenrod gall fly (Eurosta solidaginis): substrate preferences, salt effects, and $\mathrm{pH}$ effects on warm-and cold-acclimated animals. Can J Zool. 1985;63:373-9.

76. Štětina T, Hůla P, Moos M, Šimek P, Šmilauer P, Koštál V. Recovery from supercooling, freezing, and cryopreservation stress in larvae of the drosophilid fly, Chymomyza costata. Sci Rep. 2018;8:4414.

77. Koštál V, Korbelová J, Štětina T, Poupardin R, Colinet H, Zahradníčková $\mathrm{H}$, et al. Physiological basis for low-temperature survival and storage of quiescent larvae of the fruit fly Drosophila melanogaster. Sci Rep. 2016;6:32346

78. Russell RJ, Gerike U, Danson MJ, Hough DW, Taylor GL. Structural adaptations of the cold-active citrate synthase from an Antarctic bacterium. Structure. 1998;6:351-61.

79. Joanisse DR, Storey KB. Fatty acid content and enzymes of fatty acid metabolism in overwintering cold-hardy gall insects. Physiol Zool. 1996:69:1079-95.
80. McMullen DC, Storey KB. Suppression of $\mathrm{Na}^{+} \mathrm{K}^{+}$-ATPase activity by reversible phosphorylation over the winter in a freeze-tolerant insect. J Insect Physiol. 2008;54:1023-7.

81. Kadenbach B, Huttemann M. The subunit composition and function of mammalian cytochrome c oxidase. Mitochondrion. 2015;24:64-76.

82. Bourens M, Boulet A, Leary SC, Barrientos A. Human COX20 cooperates with $\mathrm{SCO} 1$ and SCO 2 to mature COX2 and promote the assembly of cytochrome c oxidase. Hum Mol Genet. 2014;23:2901-13.

83. Zeviani M, Tiranti V, Piantadosi C. Mitochondrial disorders. Medicine (Baltimore). 1998;77:59-72.

84. Kukal O, Duman JG, Serianni AS. Cold-induced mitochondrial degradation and cryoprotectant synthesis in freeze-tolerant arctic caterpillars. J Comp Physiol B. 1989;158:661-71.

85. Storey KB, Storey JM. Natural freezing survival in animals. Annu Rev Ecol Syst. 1996;27:365-86.

86. MacMillan HA, Ferguson LV, Nicolai A, Donini A, Staples JF, Sinclair BJ. Parallel ionoregulatory adjustments underlie phenotypic plasticity and evolution of Drosophila cold tolerance. J Exp Biol. 2015;218:423-32.

87. Koštál V. Cell structural modifications in insects at low temperature. In: Denlinger DL, Lee RE, editors. Low temperature biology of insects. Cambridge: Cambridge University Press; 2010. p. 116-40.

88. Tomćala A, Tollarová M, Overgaard J, Simek P, Kostál V. Seasonal acquisition of chill tolerance and restructuring of membrane glycerophospholipids in an overwintering insect: triggering by low temperature, desiccation and diapause progression. J Exp Biol. 2006;209:4102-14.

89. Chowański S, Lubawy J, Paluch-Lubawa E, Spochacz M, Rosiński G, Słocińska M. The physiological role of fat body and muscle tissues in response to cold stress in the tropical cockroach Gromphadorhina coquereliana. PLOS ONE. 2017:12:e0173100.

90. Hinkle PC. P/O ratios of mitochondrial oxidative phosphorylation. Biochimica et Biophysica Acta (BBA) - Bioenergetics. 2005;1706:1-11.

91. Rogers KD, Thompson MB, Seebacher F. Beneficial acclimation: sex specific thermal acclimation of metabolic capacity in the striped marsh frog (Limnodynastes peronii). J Exp Biol. 2007;210:2932-8.

92. Colinet $H$, Renault D, Hance T, Vernon P. The impact of fluctuating thermal regimes on the survival of a cold-exposed parasitic wasp, Aphidius colemani. Physiol Entomol. 2006;31:234-40.

93. Cheslock A, Andersen MK, MacMillan HA. Thermal acclimation alters $\mathrm{Na}^{+} / \mathrm{K}^{+}$-ATPase activity in a tissue-specific manner in Drosophila melanogaster. Comp Biochem Physiol A Mol Integr Physiol. 2021;256:110934-41.

94. MacMillan HA, Williams CM, Staples JF, Sinclair BJ. Reestablishment of ion homeostasis during chill-coma recovery in the cricket Gryllus pennsylvanicus. Proc Natl Acad Sci USA. 2012;109:20750-5.

95. Koštá V, Zahradnícková H, Šimek P, Zelený J. Multiple component system of sugars and polyols in the overwintering spruce bark beetle,lps typographus. J Insect Physiol. 2007;53:580-6.

96. Hosler JS, Burns JE, Esch HE. Flight muscle resting potential and speciesspecific differences in chill-coma. J Insect Physiol. 2000;46:621-7.

97. MacMillan HA, Sinclair BJ. The role of the gut in insect chilling injury: cold-induced disruption of osmoregulation in the fall field cricket, Gryllus pennsylvanicus. J Exp Biol. 2011;214:726-34

98. Li Q, Pogwizd SM, Prabhu SD, Zhou L. Inhibiting $\mathrm{Na}^{+} / \mathrm{K}^{+}$ATPase can impair mitochondrial energetics and induce abnormal $\mathrm{Ca}^{2+}$ cycling and automaticity in guinea pig cardiomyocytes. PLoS ONE. 2014;9:e93928.

99. MacMillan HA, Knee JM, Dennis AB, Udaka H, Marshall KE, Merritt TJ, et al. Cold acclimation wholly reorganizes the Drosophila melanogaster transcriptome and metabolome. Sci Rep. 2016;6:28999.

100. Neupane P, Bhuju S, Thapa N, Bhattarai HK. ATP synthase: structure, function and inhibition. Biomol Concepts. 2019;10:1-10.

101. Skulachev VP. Role of uncoupled and non-coupled oxidations in maintenance of safely low levels of oxygen and its one-electron reductants. Q Rev Biophys. 1996:29:169-202.

102. Słocińska M, Antos-Krzemińska N, Rosiński G, Jarmuszkiewicz W. Identification and characterization of uncoupling protein 4 in fat body and muscle mitochondria from the cockroach Gromphadorhina cocquereliana. J Bioenerg Biomembr. 2011;43:717-27.

103. Kayukawa T, Ishikawa Y. Chaperonin contributes to cold hardiness of the onion maggot Delia antiqua through repression of depolymerization of actin at low temperatures. PLoS ONE. 2009;4:e8277. 
104. Dumas P, Morin MD, Boquel S, Moffat CE, Morin P. Expression status of heat shock proteins in response to cold, heat, or insecticide exposure in the Colorado potato beetle Leptinotarsa decemlineata. Cell Stress Chaperones. 2019;24:539-47.

105. Teets NM, Kawarasaki Y, Lee RE, Denlinger DL. Survival and energetic costs of repeated cold exposure in the Antarctic midge, Belgica antarc tica: a comparison between frozen and supercooled larvae. J Exp Biol. 2011;214:806-14.

106. Colinet H, Lee SF, Hoffmann A. Temporal expression of heat shock genes during cold stress and recovery from chill coma in adult Drosophila melanogaster. FEBS J. 2010;277:174-85.

107. Lu MX, Li HB, Zheng YT, Shi L, Du YZ. Identification, genomic organization and expression profiles of four heat shock protein genes in the western flower thrips, Frankliniella occidentalis. J Therm Biol. 2016;57:110-8.

108. Tan Y, Zhang Y, Huo ZJ, Zhou XR, Pang BP. Molecular cloning of heat shock protein 10 (Hsp10) and 60 (Hsp60) cDNAs from Galeruca daurica (Coleoptera: Chrysomelidae) and their expression analysis. Bull Entomol Res. 2018;108:510-22.

109. Cai ZL, Chen JX, Cheng J, Lin T. Overexpression of three heat shock proteins protects Monochamus alternatus (Coleoptera: Cerambycidae) from thermal stress. J Insect Sci. 2017;17:113.

110. Sinclair BJ, Gibbs AG, Roberts SP. Gene transcription during exposure to, and recovery from, cold and desiccation stress in Drosophila melanogaster. Insect Mol Biol. 2007;16:435-43.

111. Yocum GD, Joplin KH, Denlinger DL. Upregulation of a 23 kDa small heat shock protein transcript during pupal diapause in the flesh fly, Sarcophaga, crassipalpis. Insect Biochem Mol Biol. 1998;28:677-82.

112. Jia H, Ma M, Zhai N, Liu Z, Wang H, Guo X, et al. Roles of a mitochondrial $\mathrm{AccSCO}_{2}$ gene from Apis cerana cerana in oxidative stress responses. J Inorg Biochem. 2017;175:9-19.

113. Zhang G, Storey JM, Storey KB. Chaperone proteins and winter survival by a freeze tolerant insect. J Insect Physiol. 2011;57:1115-22.

114. Joanisse D, Storey K. Oxidative stress and antioxidants in overwintering larvae of cold-hardy goldenrod gall insects. J Exp Biol. 1996;199:1483-91.

115. Lalouette L, Williams CM, Hervant F, Sinclair BJ, Renault D. Metabolic rate and oxidative stress in insects exposed to low temperature thermal fluctuations. Comp Biochem Physiol A Mol Integr Physiol. 2011;158:229-34.

116. Chowański S, Lubawy J, Spochacz M, Paluch E, Smykalla G, Rosiński G, et al. Cold induced changes in lipid, protein and carbohydrate levels in the tropical insect Gromphadorhina coquereliana. Comp Biochem Physiol A Mol Integr Physiol. 2015;183:57-63.

117. Jiang $X$, Zhai H, Wang L, Luo L, Sappington TW, Zhang L. Cloning of the heat shock protein 90 and 70 genes from the beet armyworm, Spodoptera exigua, and expression characteristics in relation to thermal stress and development. Cell Stress Chaperones. 2012;17:67-80.

118. Abele D, Puntarulo S. Formation of reactive species and induction of antioxidant defence systems in polar and temperate marine invertebrates and fish. Comp Biochem Physiol A Mol Integr Physiol. 2004;138:405-15.

119. Jia HH, Sun RJ, Shi WN, Yan Y, Li H, Guo XQ, et al. Characterization of a mitochondrial manganese superoxide dismutase gene from Apis cerana cerana and its role in oxidative stress. J Insect Physiol. 2014;60:68-79.

120. Rojas RR, Leopold RA. Chilling injury in the housefly: evidence for the role of oxidative stress between pupariation and emergence. Cryobiology. 1996;33:447-58.

121. Jing $\mathrm{XH}$, Wang $\mathrm{XH}$, Kang L. Chill injury in the eggs of the migratory locust, Locusta migratoria (Orthoptera: Acrididae): the time-temperature relationship with high-temperature interruption. Insect Sci. 2005:12:171-8.

122. Słocińska M, Barylski J, Jarmuszkiewicz W. Uncoupling proteins of invertebrates: a review. IUBMB Life. 2016;68:691-9.

123. Mailloux RJ, Harper ME. Uncoupling proteins and the control of mitochondrial reactive oxygen species production. Free Radic Biol Med. 2011;51:1106-15.

124. Alves-Bezerra M, Cosentino-Gomes D, Vieira LP, Rocco-Machado N, Gondim KC, Meyer-Fernandes JR. Identification of uncoupling protein 4 from the blood-sucking insect Rhodnius prolixus and its possible role on protection against oxidative stress. Insect Biochem Mol Biol. 2014,50:24-33.

125. Joanisse DR, Storey KB. Oxidative stress and antioxidants in stress and recovery of cold-hardy insects. Insect Biochem Mol Biol. 1998;28:23-30.

126. Lopez-Martinez G, Elnitsky MA, Benoit JB, Lee RE, Denlinger DL. High resistance to oxidative damage in the Antarctic midge Belgica antarctica, and developmentally linked expression of genes encoding superoxide dismutase, catalase and heat shock proteins. Insect Biochem Mol Biol. 2008;38:796-804.

127. Zhao L, Jones WA. Expression of heat shock protein genes in insect stress responses. Isj-Invertebrate Survival Journal. 2012;9:93-101.

128. Guo XJ, Feng JN. Comparisons of expression levels of heat shock proteins (hsp70 and hsp90) from Anaphothrips obscurus (Thysanoptera: Thripidae) in polymorphic adults exposed to different heat shock treatments. J Insect Sci. 2018;18:15.

129. Zhang B, Peng Y, Zheng J, Liang L, Hoffmann AA, Ma C-S. Response of heat shock protein genes of the oriental fruit moth under diapause and thermal stress reveals multiple patterns dependent on the nature of stress exposure. Cell Stress Chaperones. 2016;21:653-63.

130. Yi J, Wu H, Liu J, Lai X, Guo J, Li D, et al. Molecular characterization and expression of six heat shock protein genes in relation to development and temperature in Trichogramma chilonis. PLoS ONE. 2018;13:e0203904.

131. King AM, MacRae TH. Insect heat shock proteins during stress and diapause. Annu Rev Entomol. 2015:60:59-75.

132. Goto SG, Kimura MT. Heat- and cold-shock responses and temperature adaptations in subtropical and temperate species of Drosophila. J Insect Physiol. 1998;44:1233-9.

133. Kimura MT, Yoshida KM, Goto SG. Accumulation of Hsp70 mRNA under environmental stresses in diapausing and nondiapausing adults of Drosophila triauraria. J Insect Physiol. 1998:44:1009-15.

134. Parsell DA, Lindquist S. The function of heat-shock proteins in stress tolerance: degradation and reactivation of damaged proteins. Annu Rev Genet. 1993;27:437-96.

135. Hartl FU, Bracher A, Hayer-Hartl M. Molecular chaperones in protein folding and proteostasis. Nature. 2011;475:324-32.

136. Fink AL. Chaperone-mediated protein folding. Physiol Rev. 1999:79:425-49.

137. De Maio A. Heat shock proteins: facts, thoughts, and dreams. Shock. 1999;11:1-12.

138. Renner T, Waters ER. Comparative genomic analysis of the Hsp70s from five diverse photosynthetic eukaryotes. Cell Stress Chaperones. 2007; 12:172-85.

139. Wong CS, Mak CH, Ko RC. Cloning and characterization of the mitochondrial heat-shock protein 60 gene of Trichinella spiralis. Parasitol Res. 2004:93:461-7.

140. Morrow G, Inaguma Y, Kato K, Tanguay RM. The small heat shock protein Hsp22 of Drosophila melanogaster is a mitochondrial protein displaying oligomeric organization. J Biol Chem. 2000;275:31204-10.

141. Qin W, Neal SJ, Robertson RM, Westwood JT, Walker VK. Cold hardening and transcriptional change in Drosophila melanogaster. Insect Mol Biol. 2005;14:607-13

142. Colinet $\mathrm{H}$, Lee SF, Hoffmann A. Knocking down expression of Hsp22 and $\mathrm{Hsp} 23$ by RNA interference affects recovery from chill coma in Drosophila melanogaster. J Exp Biol. 2010;213:4146-50.

143. Morrow G, Samson M, Michaud S, Tanguay RM. Overexpression of the small mitochondrial Hsp22 extends Drosophila life span and increases resistance to oxidative stress. FASEB J. 2004;18:598-9.

144. Miura M. Apoptotic and nonapoptotic caspase functions in animal development. Cold Spring Harbor Perspect Biol. 2012;4:a008664.

145. Xu Q, Qin Y. Molecular cloning of heat shock protein 60 (PtHSP60) from Portunus trituberculatus and its expression response to salinity stress. Cell Stress Chaperones. 2012;17:589-601.

146. Cheng MY, Hartl FU, Martin J, Pollock RA, Kalousek F, Neupert W, et al. Mitochondrial heat-shock protein hsp60 is essential for assembly of proteins imported into yeast mitochondria. Nature. 1989;337:620-5.

147. Jebara F, Weiss C, Azem A. Hsp60 and Hsp70 chaperones: guardians of mitochondrial proteostasis. eLS. 2017:1-9.

148. Böttinger L, Oeljeklaus S, Guiard B, Rospert S, Warscheid B, Becker T. Mitochondrial heat shock protein (Hsp) 70 and Hsp10 cooperate in the formation of Hsp60 complexes. J Biol Chem. 2015;290:11611-22. 
149. Corrao S, Campanella C, Anzalone R, Farina F, Zummo G, Conway de

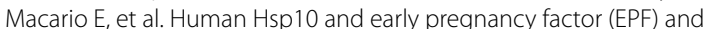
their relationship and involvement in cancer and immunity: current knowledge and perspectives. Life Sci. 2010;86:145-52.

150. Clare DK, Saibil HR. ATP-driven molecular chaperone machines. Biopolymers. 2013;99:846-59.

151. Hayer-Hartl M, Bracher A, Hartl FU. The GroEL-GroES chaperonin machine: a nano-cage for protein folding. Trends Biochem Sci. 2016:41:62-76.

152. Clavier A, Rincheval-Arnold A, Colin J, Mignotte B, Guenal I. Apoptosis in Drosophila: which role for mitochondria? Apoptosis. 2016;21:239-51.

153. Bayley JS, Winther CB, Andersen MK, Gronkjaer C, Nielsen OB, Pedersen $\mathrm{TH}$, et al. Cold exposure causes cell death by depolarization-mediated $\mathrm{Ca}^{2+}$ overload in a chill-susceptible insect. Proc Natl Acad Sci U S A. 2018;115:E9737-44.

154. Kumarswamy R, Seth RK, Dwarakanath BS, Chandna S. Mitochondrial regulation of insect cell apoptosis: evidence for permeability transition pore-independent cytochrome-c release in the Lepidopteran Sf9 cells. Int J Biochem Cell Biol. 2009;41:1430-40.

155. Ostermann J, Horwich AL, Neupert W, Hartl FU. Protein folding in mitochondria requires complex-formation with $\mathrm{Hsp} 60$ and ATP hydrolysis. Nature. 1989;341:125-30.

156. Arya R, Lakhotia SC. Hsp60D is essential for caspase-mediated induced apoptosis in Drosophila melanogaster. Cell Stress Chaperones. 2008;13:509-26.

157. Concannon CG, Gorman AM, Samali A. On the role of Hsp27 in regulating apoptosis. Apoptosis. 2003;8:61-70.

158. Cogliati S, Enriquez JA, Scorrano L. Mitochondrial cristae: where beauty meets functionality. Trends Biochem Sci. 2016:41:261-73.

159. Friedman JR, Nunnari J. Mitochondrial form and function. Nature. 2014:505:335-43.

160. Bosetti F, Baracca A, Lenaz G, Solaini G. Increased state 4 mitochondrial respiration and swelling in early post-ischemic reperfusion of rat heart. FEBS Lett. 2004;563:161-4.

161. Jiang YF, Lin SS, Chen JM, Tsai HZ, Hsieh TS, Fu CY. Electron tomographic analysis reveals ultrastructural features of mitochondrial cristae architecture which reflect energetic state and aging. Sci Rep. 2017;7:45474

162. Virolainen E, Blokhina O, Fagerstedt K. Ca2+-induced high amplitude swelling and cytochrome $\mathrm{C}$ release from wheat (Triticum aestivum L.) mitochondria under anoxic stress. Ann Bot. 2002;90:509-16.

163. Arimura S, Kurisu R, Sugaya H, Kadoya N, Tsutsumi N. Cold treatment induces transient mitochondrial fragmentation in Arabidopsis thaliana in a way that requires DRP3A but not ELM1 or an ELM1-like homologue, ELM2. Int J Mol Sci. 2017;18:2161.

164. Logan DC, Leaver CJ. Mitochondria-targeted GFP highlights the heterogeneity of mitochondrial shape, size and movement within living plant cells. J Exp Bot. 2000;51:865-71.

165. O'Brien KM. Mitochondrial biogenesis in cold-bodied fishes. J Exp Biol. 2011:214:275-85

166. Levin DB, Danks HV, Barber SA. Variations in mitochondrial DNA and gene transcription in freezing-tolerant larvae of Eurosta solidaginis (Diptera: Tephritidae) and Gynaephora groenlandica (Lepidoptera: Lymantriidae). Insect Mol Biol. 2003;12:281-9.

167. Bennett VA, Kukal O, Lee RE. Metabolic opportunists: feeding and temperature influence the rate and pattern of respiration in the high arctic woollybear caterpillar gynaephora groenlandica (Lymantriidae). J Exp Biol. 1999:202:47-53.

168. Abdelwahid E, Yokokura T, Krieser RJ, Balasundaram S, Fowle WH, White K. Mitochondrial disruption in Drosophila apoptosis. Dev Cell. 2007;12:793-806.

169. Sesso A, Belizario JE, Marques MM, Higuchi ML, Schumacher RI, Colquhoun A, et al. Mitochondrial swelling and incipient outer membrane rupture in preapoptotic and apoptotic cells. Anat Rec (Hoboken). 2012:295:1647-59.

170. Lee RE, Allenspach AL, Collins SD. Ultrastructural effects of lethal freezing on brain, muscle and Malpighian tubules from freeze-tolerant larvae of the gall fly, Eurosta solidaginis. J Insect Physiol. 1997;43:39-45.

171. Arrese EL, Soulages JL. Insect fat body: energy, metabolism, and regulation. Annu Rev Entomol. 2010:55:207-25.
172. Vanin S, Bubacco L, Beltramini M. Seasonal variation of trehalose and glycerol concentrations in winter snow-active insects. Cryo Letters. 2008:29:485-91.

173. Storey KB. Organic solutes in freezing tolerance. Comp Biochem Physiol A Physiol. 1997;117:319-26.

174. Goto M, Li YP, Kayaba S, Outani S, Koichi S. Cold hardiness in summer and winter diapause and post-diapause pupae of the cabbage armyworm, Mamestra brassicae L. under temperature acclimation. J Insect Physiol. 2001;47:709-14.

\section{Publisher's Note}

Springer Nature remains neutral with regard to jurisdictional claims in published maps and institutional affiliations.
Ready to submit your research? Choose BMC and benefit from:

- fast, convenient online submission

- thorough peer review by experienced researchers in your field

- rapid publication on acceptance

- support for research data, including large and complex data types

- gold Open Access which fosters wider collaboration and increased citations

- maximum visibility for your research: over $100 \mathrm{M}$ website views per year

At BMC, research is always in progress.

Learn more biomedcentral.com/submissions 